\title{
$\beta 1$ Integrin Signaling Maintains Human Epithelial Progenitor Cell Survival In Situ and Controls Proliferation, Apoptosis and Migration of Their Progeny
}

\author{
Nancy Ernst ${ }^{1}$, Arzu Yay ${ }^{2}$, Tamás Bíró ${ }^{3}$, Stephan Tiede ${ }^{4}$, Martin Humphries ${ }^{5}$, Ralf Paus ${ }^{1,6^{*}}$, Jennifer E. \\ Kloepper ${ }^{10}$
}

1 Department of Dermatology, University of Luebeck, Luebeck, Germany, 2 Department of Histology and Embryology, University of Erciyes, Kayseri, Turkey, 3 DE-MTA "Lendület" Cellular Physiology Group, Department of Physiology, University of Debrecen, Debrecen, Hungary, 4 Institute of Experimental Immunology, Euroimmun AG, Luebeck, Germany, $\mathbf{5}$ Faculty of Life Sciences, University of Manchester, Manchester, United Kingdom, $\mathbf{6}$ Institute of Inflammation and Repair, University of Manchester, Manchester, United Kingdom

\begin{abstract}
$\beta 1$ integrin regulates multiple epithelial cell functions by connecting cells with the extracellular matrix (ECM). While $\beta 1$ integrin-mediated signaling in murine epithelial stem cells is well-studied, its role in human adult epithelial progenitor cells (ePCs) in situ remains to be defined. Using microdissected, organ-cultured human scalp hair follicles (HFs) as a clinically relevant model for studying human ePCs within their natural topobiological habitat, $\beta 1$ integrin-mediated signaling in ePC biology was explored by $\beta 1$ integrin siRNA silencing, specific $\beta 1$ integrin-binding antibodies and pharmacological inhibition of integrin-linked kinase (ILK), a key component of the integrin-induced signaling cascade. $\beta 1$ integrin knock down reduced keratin 15 (K15) expression as well as the proliferation of outer root sheath keratinocytes (ORSKs). Embedding of HF epithelium into an ECM rich in $\beta 1$ integrin ligands that mimic the HF mesenchyme significantly enhanced proliferation and migration of ORSKs, while K15 and CD200 gene and protein expression were inhibited. Employing ECM-embedded $\beta 1$ integrin-activating or -inhibiting antibodies allowed to identify functionally distinct human ePC subpopulations in different compartments of the HF epithelium. The $\beta 1$ integrin-inhibitory antibody reduced $\beta 1$ integrin expression in situ and selectively enhanced proliferation of bulge ePCs, while the $\beta 1$ integrin-stimulating antibody decreased hair matrix keratinocyte apoptosis and enhanced transferrin receptor (CD71) immunoreactivity, a marker of transit amplifying cells, but did not affect bulge ePC proliferation. That the putative ILK inhibitor QLT0267 significantly reduced ORSK migration and proliferation and induced massive ORSK apoptosis suggests a key role for ILK in mediating the ß1 integrin effects. Taken together, these findings demonstrate that ePCs in human HFs require $\beta 1$ integrin-mediated signaling for survival, adhesion, and migration, and that different human HF ePC subpopulations differ in their response to $\beta 1$ integrin signaling. These insights may be exploited for cell-based regenerative medicine strategies that employ human HF-derived ePCs.
\end{abstract}

Citation: Ernst N, Yay A, Bíró T, Tiede S, Humphries M, et al. (2013) $\beta 1$ Integrin Signaling Maintains Human Epithelial Progenitor Cell Survival In Situ and Controls Proliferation, Apoptosis and Migration of Their Progeny. PLoS ONE 8(12): e84356. doi:10.1371/journal.pone.0084356

Editor: Effie C Tsilibary, National Center for Scientific Research Demokritos, Greece

Received July 11, 2013; Accepted November 14, 2013; Published December 27, 2013

Copyright: @ 2013 Ernst et al. This is an open-access article distributed under the terms of the Creative Commons Attribution License, which permits unrestricted use, distribution, and reproduction in any medium, provided the original author and source are credited.

Funding: This study was supported by a fellowship of the medical faculty of the University of Luebeck to J.K. (E42-2010) and a grant from the DFG (PA 345/13-1) to RP. The funders had no role in study design, data collection and analysis, decision to publish, or preparation of the manuscript.

Competing interests: The authors have declared that no competing interests exist.

*E-mail: ralf.paus@uksh.de

๑ These authors contributed equally to this work.

\section{Introduction}

Integrins are transmembrane receptors that link the extracellular matrix (ECM) environment with intracellular signaling, thus regulating multiple cell functions such as cell survival, proliferation, migration, and differentiation [1-3]. $18 \alpha$ and $8 \beta$ mammalian integrin subunits have been identified so far, which can assemble to 24 different heterodimers with different affinities toward specific ECM components [4-7]. The extracellular binding activity is regulated intracellularly (insideout signaling), while extracellular binding of the ECM triggers signals that are transmitted into the cell (outside-in signaling) $[6,8,9]$. When specific ECM ligands bind to the extracellular region, integrin receptors cluster in the cell membrane and the cytoplasmic part of the integrin complex sends signals to the actin cytoskeleton and forms focal adhesions (FAs) [10,11].

Defined ECMs in adult tissues (niches) are likely to be the first molecular components interacting with stem cells (SCs) 
$[12,13]$. These niches regulate adult SC-preservation and/or differentiation and by that regulating the homeostasis of tissues/organs, like the epidermis and the cyclic hair follicle (HF) $[12,14]$. $ß 1$ integrin signaling has long been thought to be important in murine epidermal and HF epithelial SCs (eSCs) [15-17]. In the HF, eSCs and partially differentiated epithelial progenitor cells (ePCs) can give rise to all epithelial cell types of the hair, the epidermis, and the sebaceous gland and are mostly found within the HF bulge [18-20]. The eSCs within this HF compartment $[16,21]$ are slow-cycling, and show clonogenicity and proliferative capacity [22]. Potential markers for the epithelial HF SCs include $\beta 1$ integrin, keratin 15 and 19 (K15, K19), a6 integrin, the transferrin receptor (CD71), p63 and CD34; however there is still considerable debate over how to distinguish the least committed, slow-cycling eSCs from their immediate progeny (i.e., rapidly proliferating, but more committed transit amplifying cells) [23-27].

Previous work has suggested that epithelial cells in human epidermis with the highest level of $\alpha 2 \beta 1, \alpha 3 \beta 1$ and $\alpha 5 \beta 1$ integrin expression show a high colony-forming efficiency (CFE) [28], and that $ß 1$ integrin signaling is absolutely required for epidermal and HF maintenance in mice [3]. However, the role of $\beta 1$ integrin signaling in human ePC maintenance or differentiation, namely in human HFs, remains to be clarified, since the bulge region of human scalp HFs does not express markedly more $B 1$ integrin protein than other regions of the basal layer of the human outer root sheath (ORS) [16,29].

Potential ligands for integrins expressed on HF keratinocytes are components of the basement membrane (BM) that separates the HF epithelium from its surrounding mesenchyme, the connective tissue sheath (CTS). These BMassociated integrin ligands include collagen IV, laminin-5, perlecan and nidogen $[3,30]$. Thus, ORS keratinocytes (ORSKs) can interact with multiple ECM components of the BM via $\alpha 2 \beta 1, \alpha 3 \beta 1$, and $\alpha 6 \beta 4$ integrins, which are differentially expressed in distinct regions of the HF [31,32]. $\alpha 3 \beta 1$ integrins connect the actin cytoskeleton to the $\mathrm{BM}$ via binding laminin-5, whereas the $\alpha 2 \beta 1$ integrin is found in basal keratinocytes, where it is thought to mediate cell-cell interactions and BM attachment via collagens $[4,15,32]$.

On this background, we have further explored the role of $\beta 1$ integrin-mediated signaling in the human HF epithelium in situ, exploiting organ-cultured human scalp HFs as an easily accessible mini-organ that represent a prototypic neuroectodermal-mesodermal interaction system in which various ePC populations can be studied within their natural tissue habitat $[29,33,34]$. Specifically, we wished to elucidate the impact of manipulating the outside-in signaling of $\beta 1$ integrin via different ligands on the maintenance, differentiation and/or migration of distinct human ePC subpopulations in situ.

This was investigated by $ß 1$ integrin silencing in full-length human scalp HFs, which permits one to evaluate the role of $ß 1$ integrin in ePCs within their intact human HF SC niche. In addition, dispase-pretreated organ-cultured adult human scalp HF epithelium, which lacks normal HF BM and mesenchyme,

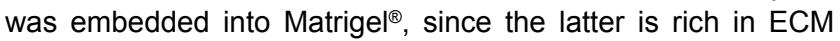
components that are also found in the HF's CTS and BM, such as laminin, collagen IV, heparin sulfate proteoglycans, entactin, and growth factors [12,35], with collagen I added for structural support and for mimicking any signaling input of dermal collagen. This was done in the absence or presence of activating or inhibiting $ß 1$ integrin antibodies (see Text S1). Downstream $\quad$ 1 integrin-mediated signaling was pharmacologically disrupted with QLT0267 (DERMIRA, [36-38]), which was developed as a putative ILK (integrinlinked kinase) inhibitor, a key adaptor protein that interacts with the cytoplasmic domains of $\beta 1$ and $\beta 3$ integrins and regulates many cellular processes by connecting $\beta 1$ integrin with other regulatory and adaptor proteins like Pinch, $\alpha$ - and $\beta$-parvins [39-41].

\section{Materials and Methods}

\section{Hair follicle collection}

All experiments were performed adhering to the Declaration of Helsinki Principles, and with the University of Luebeck ethics committee approval (06-109). HFs were isolated from human scalp skin obtained from routine face-lift surgery (from 12 female patients aged 19-75 years, mean age 50.2 years) after written consent.

\section{$\boldsymbol{\beta} 1$ integrin silencing}

In 3 experiments, whole HFs were cut out of human scalp skin and transfected once with a pool of 3 human $\beta 1$ integrinspecific siRNAs (Santa Cruz, sc-35674). HFs treated with control siRNA conjugated with FITC (Santa Cruz, sc-36869) served as a scrambled control in comparison to HFs which were just cultured in transfection medium. After transfection HFs were maintained in a 6 -well-plate with $3 \mathrm{ml}$ William's $\mathrm{E}$ medium (Biochrom) supplemented with $1 \%$ L-glutamine (Invitrogen), $\quad 0.02 \%$ hydrocortisone (Sigma-Aldrich), $0.1 \%$ insulin (Sigma-Aldrich) and 1\% penicillin/streptomycin mixture (Gibco, [34]). All reagents essential for transfection were obtained from Santa Cruz Biotechnology (siRNA transfection reagent, sc-29528; siRNA transfection medium, sc-36868).

\section{Isolation and culturing of human hair follicles in an extracellular matrix assay}

HF epithelium was isolated after dispase-pretreatment $(0.1 \%$ $(w / v)$ in William's $E$ medium without penicillin/streptomycin over night at $4^{\circ} \mathrm{C}$ and embedded into an artificial and BM mimicking ECM system, a mixture of Matrige $^{\circledR}$ (BD Biosciences) and collagen I (ratio 1:1) in keratinocyte serum-free medium (KSFM). The embedded HFs were cultured over 4 days in the presence or absence of the two different $\beta 1$ integrin antibodies (an activating 12G10 and an inhibiting mAb13 antibody) or in the presence or absence of the ILK inhibitor QLT0267 in comparison to standard organ-cultured HFs (in supplemented William's E medium) [42].

The concentration of $10 \mu \mathrm{g} / \mathrm{ml}$ for $12 \mathrm{G} 10$ and $\mathrm{mAb} 13$ was already described as effective and established for HF organ cultures in a previous study of our lab [29] while the application of the ILK inhibitor QLT0267 concentration was chosen empirically. Adapting previous studies [36-38,43,44] which only describe different concentrations used for QLT0267 in cell 
culture experiments, we chose a high concentration of $100 \mu \mathrm{M}$ (dissolved in DMSO [Dimethyl sulfoxide]) being most effective in this complexity of an embedded mini-organ as the HF with its outgrowing cells. We expected that the inhibitor penetration into the tissue would be more difficult than into cultured cells. The scarcity of human HFs available for experimentation generally prohibits running of dose response studies.

During the culture we analyzed HF cell outgrowth by measuring the whole area around the HF and the two largest outgrowth points starting from the hair shaft (HF bulb, upper $\mathrm{HF}$ ) every second day.

\section{Immunofluorescence and immunohistochemical analysis}

Cultured whole HFs were cryosectioned $(6 \mu \mathrm{m})$ and embedded HFs were cryosectioned $(8 \mu \mathrm{m})$. The immunoreactivity (IR) pattern of endogenous $\beta 1$ integrin (12G10, 1:500; kindly given by the Humphries' lab), keratin 15 (K15) (1:400, Chemicon, CBL), K6 (1:400, Progen), CD200biotin (1:25, serotec), ILK (1:100, Epitomics), CD71-PE (1:100, BD Pharmingen), cleaved caspase 3 (1:400, Cell Signaling), cortactin-alexa fluor 488 (1:400, Millipore), Ki-67 and TUNEL were quantified [34]. For the quantification of the IR pattern of $\beta 1$ integrin inhibitory and stimulatory antibody treated HFs a labelling of the primary antibodies, which was not already coupled with a fluorochrome or signaling molecule (biotin), was necessary. The primary antibodies against K15 and K6 were covalently attached with biotin by using the APEX ${ }^{\circledR}$ Antibody Labeling Kit (Invitrogen, Biotin-XX, cat.no. A10495).

\section{5-ethynyl-2'-deoxyuridine incorporation}

A more specific method to detect cell proliferation is the quantifying of only S-phase active and DNA-synthesizing cells [45]. By using 5-ethynyl-2'-deoxyuridine (EdU), a terminal nucleoside analog of thymidine, its incorporation during active DNA synthesis [46] could be visualized because of its labeling with a stabile fluorescence dye. The whole method was performed following the manufacture's guidelines (Click-iT® EdU Alexa Fluor@ 488 Flow Cytometry Assay Kit, Invitrogen).

\section{Quantitative real-time PCR for expression analysis of $\beta 1$ integrin, K15, CD200, and K6}

The total RNA of $12 \mathrm{HFs}$ per condition, cultured in William's $E$ medium or embedded in the aECM (artificial extracellular matrix) assay was extracted by using TRIreagent (Applied Biosystems/Life Technologies) and digested with recombinant RNase-free DNase-1 (Applied Biosystems) according to the manufacturer's protocol. $1 \mu \mathrm{g}$ of total, isolated RNA was reverse transcribed into cDNA with High Capacity cDNA kit (Applied Biosystems) following the manufacturer's protocol. By using specific TaqMan primers and probes (Applied Biosystems, assay IDs: Hs00559595_m1 for human $\beta 1$ integrin, Hs00267035_m1 for human Keratin 15, Hs01033303_m1 for human CD200 and Hs01699178_g1 for human Keratin 6) PCR amplification was performed. As internal housekeeping gene controls, transcripts of glyceraldehyde 3phosphate dehydrogenase (GAPDH), peptidylprolyl isomerase A (PPIA) or $\beta$-actin were determined (assay IDs: Hs99999903 for human ACTB, Hs99999904 for human PPIA and Hs99999905_m1 for human GAPDH). The amount of the above mentioned transcripts was normalized to those of the control genes using the $\Delta \mathrm{CT}$ method.

\section{Protein extraction and Western blot analysis of integrin-linked kinase}

$20 \mathrm{HFs}$ were isolated after an over night $0.1 \%(\mathrm{w} / \mathrm{v})$ dispase treatment $\left(4^{\circ} \mathrm{C}\right)$ and were washed in phosphate buffered saline (PBS), flash frozen in liquid nitrogen and lysed in buffer containing $10 \mathrm{mM}$ Tris- $\mathrm{HCl}, \mathrm{pH} 7,2,2 \%$ sodium dodecyl sulphate (SDS), 1\% Triton-X100, 10\% Glycerol and $2 \%$ Protease Inhibitor Set I. Later the samples were further homogenized by using ultra sound (power 60) for 15 seconds. After a centrifugation the supernatant was taken and protein concentrations were determined using the Pierce BCA protein assay kit.

$20 \mu \mathrm{g}$ protein lysates were then separated by electrophoresis through a $10 \%$ SDS gel and transferred to a PVDF (Polyvinylidene Difluoride) membrane. The membrane was blocked in $5 \%$ non-fat dried milk in tris buffered saline (TBS), $0.05 \%$ Tween-20, incubated in primary antibody (ILK 1:2000, Epitomics, $\beta$-actin 1:1000, Santa Cruz) overnight at $4^{\circ} \mathrm{C}$, washed in TBS $/ 0.05 \%$ Tween-20, and incubated with horseradish peroxidase (HRP)-conjugated secondary antibody (Jackson Immunoresearch Laboratories) for $1 \mathrm{~h}$ at room temperature. Secondary antibody was visualized using ECL (enhanced chemiluminescence) reagent, according to the manufacturer's instructions (GE Healthcare).

\section{Statistical analyses}

All data were given as the mean of normalized data \pm SEM (standard error of the mean) and the evaluation of statistical significance was performed by using GraphPad Prism 5.01 (Graph Pad software, Inc., San Diego, CA, USA). T-test or oneway ANOVA followed by an appropriate post hoc comparison (depending on a given Gaussian distribution) was used specifically.

\section{Results}

$\beta 1$ integrin silencing reduces proliferation and DNA synthesis in different progenitor cell populations of the human hair follicle epithelium

$\beta 1$ integrin is prominently expressed throughout the human $\mathrm{HF} B M$, including the eSC niche region of the HF $[16,17]$, and human HF ePCs from the bulge overexpress $\beta 1$ integrin mRNA $[47,48]$. Therefore, we first investigated the overall effects of $\beta 1$ integrin silencing on human ePC functions in situ within intact, full-length, organ-cultured human scalp HFs that had been transfected with a cocktail of three $\beta 1$ integrin-specific siRNAs or with scrambled control RNAs, using a standardized method that had previously been found to be effective $[49,50]$ following the manufacturer's guidelines (Santa Cruz). Successful $\beta 1$ integrin knock down in human anagen scalp HFs was demonstrated at the mRNA level on day 4 (Figure 1A), yet did 


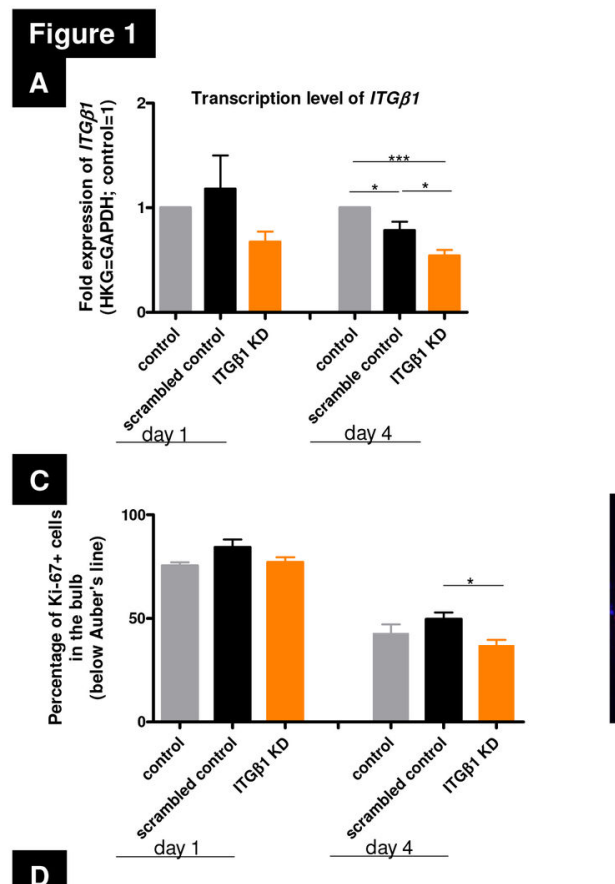

D

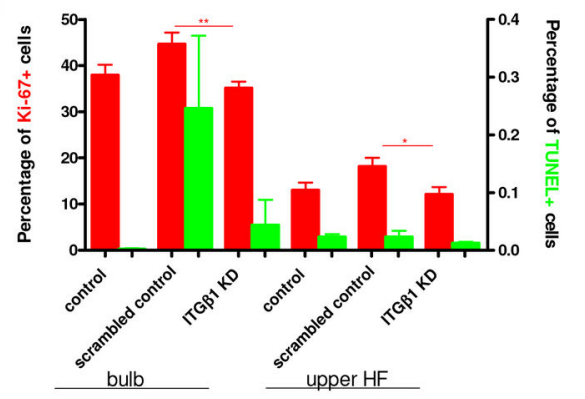

B
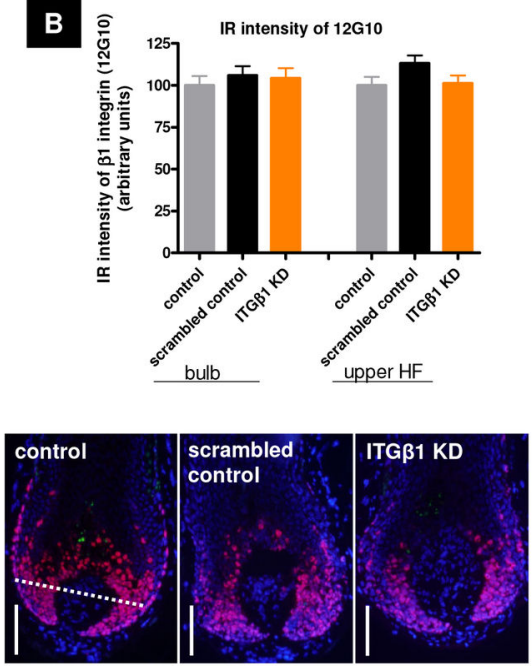

day 1
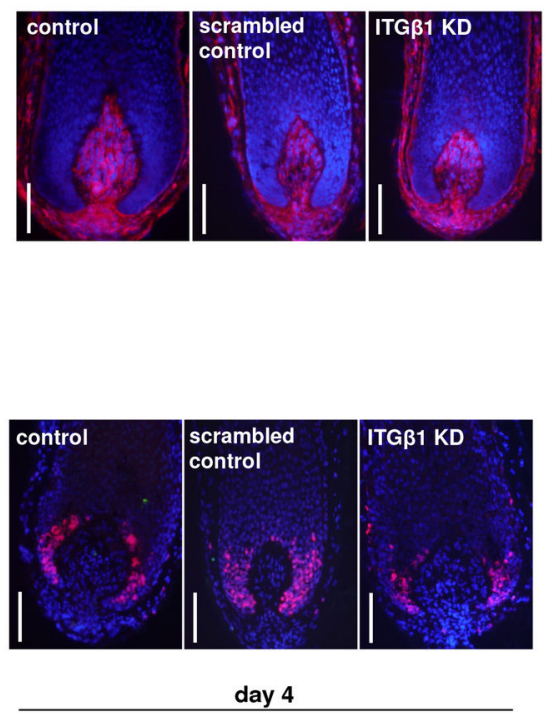

$\mathbf{E}$
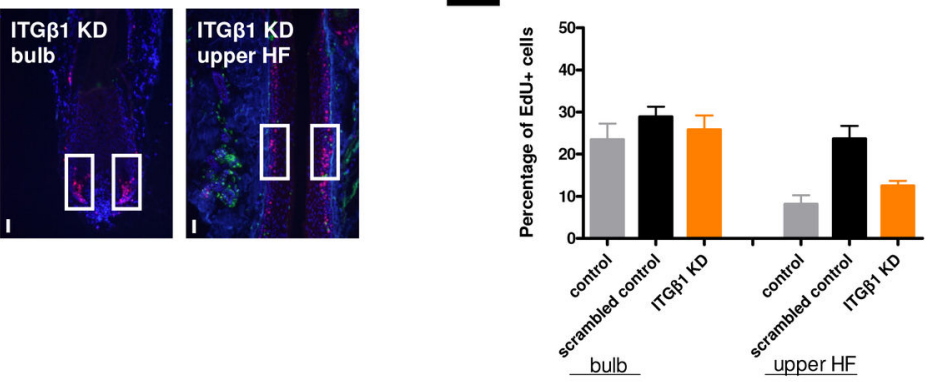

Figure 1. Gene silencing of $\boldsymbol{\beta} 1$ integrin in normal human hair follicles. (A) $B 1$ integrin gene expression was analysed with qRT-PCR using full-length hair follicles (HFs). At day1 the silencing had a strong influence on the $\beta 1$ integrin transcription of HFs, $P C R$ results on day 4 confirmed a significant silencing. Fold expression of all analyzed genes were normalized to GAPDH. $n=2-3$ individuals (for RNA extraction $12 \mathrm{HFs} /$ patient were used and cultured over 4 days). (B) The immunoreactivity (IR) pattern of $ß 1$ integrin in the whole HF was analyzed on day4 using the $B 1$ integrin-activating antibody $12 \mathrm{G} 10$. The IR intensity displayed no differences in the analyzed groups and in the different HF compartments. The control is normalized to $100 \%$. $n=17-26 \mathrm{HFs}$ of 3 individuals; representative photos of HF bulbs on day4. (C) $\beta 1$ integrin silencing caused a significant reduction of Ki-67 ${ }^{+}$matrix keratinocytes of anagen HFs (counted below Auber's line; dotted white line) treated with $\beta 1$ integrin siRNA compared to the scrambled control on day4. $n=13-16 \mathrm{HFs}$ of 3 individuals. (D) To dissect the proliferation capacity of slow-cycling epithelial progenitor cells of the HF bulge $\mathrm{Ki}-67^{+}$cells were counted in rectangles (representative photos). $\beta 1$ integrin silencing caused a significant reduction of $\mathrm{Ki}-67^{+}$cells in the bulb, but also in the HF bulge on day4. $\mathrm{n}=13-24 \mathrm{HFs}$ of 3 individuals. Red bars=Ki-67, green bars=TUNEL. (E) By analyzing the proliferating status in a human HF via counting EdU ${ }^{+}$cells in our rectangles we could show the same tendency for proliferation in $\beta 1$ integrin-mediated signaling as counting $\mathrm{Ki}-67^{+}$cells in the analyzed $\mathrm{HF}$ compartments. $\mathrm{n}=2-3 \mathrm{HFs}$ of 1 individual.

White scale bars represent $=50 \mu \mathrm{m}$. All statistical analyses were performed with the one-way ANOVA by appropriate post hoc comparison (depending on a given Gaussian distribution), mean of normalized data $+/-$ SEM $\left({ }^{*} p<0.05,{ }^{* *} p<0.01,{ }^{* * *} p<0.001\right)$. Abbreviation: $\mathrm{HKG}=$ housekeeping gene, GAPDH=glyceraldehyde3-phosphate dehydrogenase, ITG $\beta 1 \mathrm{KD}=\mathrm{knock}$ down of $\beta 1$ integrin, IR=immunoreactivity.

doi: 10.1371/journal.pone.0084356.g001

not change $ß 1$ integrin protein IR in the silenced HFs compared to controls after 4 days (Figure 1B).
The mammalian HF epithelium harbors different progenitor cell populations with distinct proliferation capacities, such as slow-cycling, intermittently proliferating ePC populations in the 
bulge versus rapidly proliferating, transit amplifying cells in the hair matrix [51,52]. Analyzing only anagen VI HFs, quantitative immunohistomorphometry of the proliferation marker Ki-67 showed that, compared to scrambled control HFs, $\beta 1$ integrinspecific silencing significantly reduced the number of $\mathrm{Ki}-67^{+}$ cells $(10 \%$ less than scrambled control) in the maximally proliferating hair matrix (Figure 1C), and also significantly reduced the number of slow-cycling $\mathrm{Ki}-67^{+}$cells in the HF bulge (Figure 1D). These results were double-checked by measuring EdU incorporation, a cell cycle S-phase specific marker to determine active DNA synthesis [46]. Counting EdU ${ }^{+}$cells in defined reference areas in the HF bulb and HF bulge, the same proliferation-inhibitory tendency after $\beta 1$ integrin silencing could be demonstrated in both HF compartments (Figure 1E, Figure S2C). Instead, $\beta 1$ integrin knock down did not significantly affect apoptosis in the HF bulb, as measured by TUNEL assay (Figure 1D).

Thus, even though $\beta 1$ integrin knock down was documented only on the mRNA level (perhaps due to extended $B 1$ integrin protein stability within the human HF), silencing was functionally effective since it reduced proliferation and DNA synthesis in both slow-cyling human bulge ePCs and rapidly proliferating human hair matrix keratinocytes in situ. This suggests that $\beta 1$ integrin may indeed operate as an important niche receptor that regulates proliferation activity in different ePC populations in the human HF.

\section{$\beta 1$ integrin-mediated signaling is required for human epithelial progenitor cell maintenance in situ}

To determine if $\beta 1$ integrin-mediated signaling is needed for the maintenance and differentiation of ePCs, we analysed the effects of $\beta 1$ integrin knock down on the expression of ePC markers K15 and CD200 [16,53,54] in human HFs in situ. Initially, i.e. one day after knock down, $\beta 1$ integrin silencing even slightly enhanced $K 15, C D 200$ and $K 6$ gene expression in human scalp HFs (Figure 2A,C,E), possibly as a temporary compensatory phenomenon. Subsequently, however, K15 transcription was significantly reduced 4 days after silencing by $\beta 1$ integrin siRNA compared to scrambled controls (Figure 2A). In the main eSC region, the HF bulge, this was also associated with a significant reduction of K15 and CD200 protein IR (Figures 2B,B1-3, Figures 2D,D1-3), suggesting that uninterrupted $B 1$ integrin signaling is required to maintain human HF eSCs within their niche.

We then investigated if $\beta 1$ integrin silencing impacts on the expression of $\mathrm{K} 6$, which is prominently and constitutively expressed by differentiated keratinocytes throughout the human ORS, but not by HF bulge eSCs $[55,56]$ and on CD71 expression, a marker of transit amplifying cells, the immediate progeny of eSCs $[57,58]$. After $\beta 1$ integrin silencing a nonspecific repression of K6 IR in both HF compartments (Figure 2E,F) can be seen and CD71 protein IR was only slightly reduced (Figure S2A). While $B 1$ integrin-mediated signaling is required to preserve the adult $\mathrm{ePC}$ pool in adult human HFs, a major overall differentiation-modulatory impact of $\beta 1$ integrin silencing could not be confirmed for $\mathrm{K} 6$ and CD71.
B1 integrin silencing does not alter expression of the hair follicle bulge immune privilege marker MHC class la

The prominent expression of the immunoinhibitory "no danger-signal", CD200 in the HF bulge [59] not only demarcates ePCs $[16,21,53]$, but also constitutes part of the relative immune privilege of the HF bulge, which may protect the HF eSC niche against autoimmune attacks and is characterized by an extremely low expression of major histocompatibility complex (MHC) class la [21,60,61]. While CD200 IR in the HF bulge was significantly reduced (Figures 2D,D1-3), $\quad \beta 1$ integrin silencing did not alter the (already minimal) MHC la IR within the human HF bulge (Figure S2B). This suggests that intact $ß 1$ integrin signaling is not essential for the maintenance of the MHC class la-based immune privilege of the human bulge.

\section{$\beta 1$ integrin ligands enhance human hair follicle keratinocyte outgrowth in situ}

Next, we investigated the influence of ECM ligands of the human HF mesenchyme (BM, CTS) that are likely to interact with $B 1$ integrin. For this purpose, human scalp HFs were treated with dispase, which cleaves collagen IV and fibronectin $[62,63]$ to remove the HF BM and CTS. The remaining denuded HF epithelium was then embedded into an ECM environment that partially mimics aspects of the native $\mathrm{HF}$ mesenchyme and BM (i.e. Matrige ${ }^{\circledR}$, which is rich in the $ß 1$ integrin ligands laminin, collagen IV, heparin sulfate proteoglycans, entactin, and growth factors [12,35,64], combined for greater stability with collagen I which represents the main dermal collagen). Both components were diluted in $\mathrm{K}$ SFM, which is optimized for the isolation and expansion of human keratinocytes [65]. The outgrowth of ORSKs from plated human HF epithelium was measured planimetrically during three different time points. This demonstrated that only the HFs embedded into an aECM, consisting of Matrige ${ }^{\circledR}$ and collagen I, showed marked ORSK outgrowth of the whole HF area (Figure $3 \mathbf{A}, \mathbf{B}$ ). This suggests that ECM-mediated signaling via integrins expressed on ORSKs is indispensable for ORSK migration in situ.

Interestingly, the addition of anti- $\beta 1$ integrin antibodies (namely, the specific ß1 integrin activating [12G10] or inhibiting [mAb13] antibodies [66,67]) enhanced the ORSK outgrowth area compared to the dispase-pretreated HF epithelium not embedded into aECM ("vehicle control"), but it showed significantly less outgrowth compared to denuded HFs embedded in aECM. Surprisingly, both activating and inhibiting B1 integrin antibodies had very similar stimulatory effects on the ORSK area outgrowth (of the whole HF) (Figure 3A).

\section{$\beta 1$ integrin receptor ligands differentially regulate epithelial cell proliferation and apoptosis in distinct human hair follicle compartments}

Since outside-in signaling via $\beta 1$ integrin regulates many fundamental epithelial cell functions $[6,68]$, we sought to correlate the observed differences in ORSK outgrowth to proliferation and apoptosis markers. When the dispasepretreated HF epithelium embedded in the CTS- and BM- 

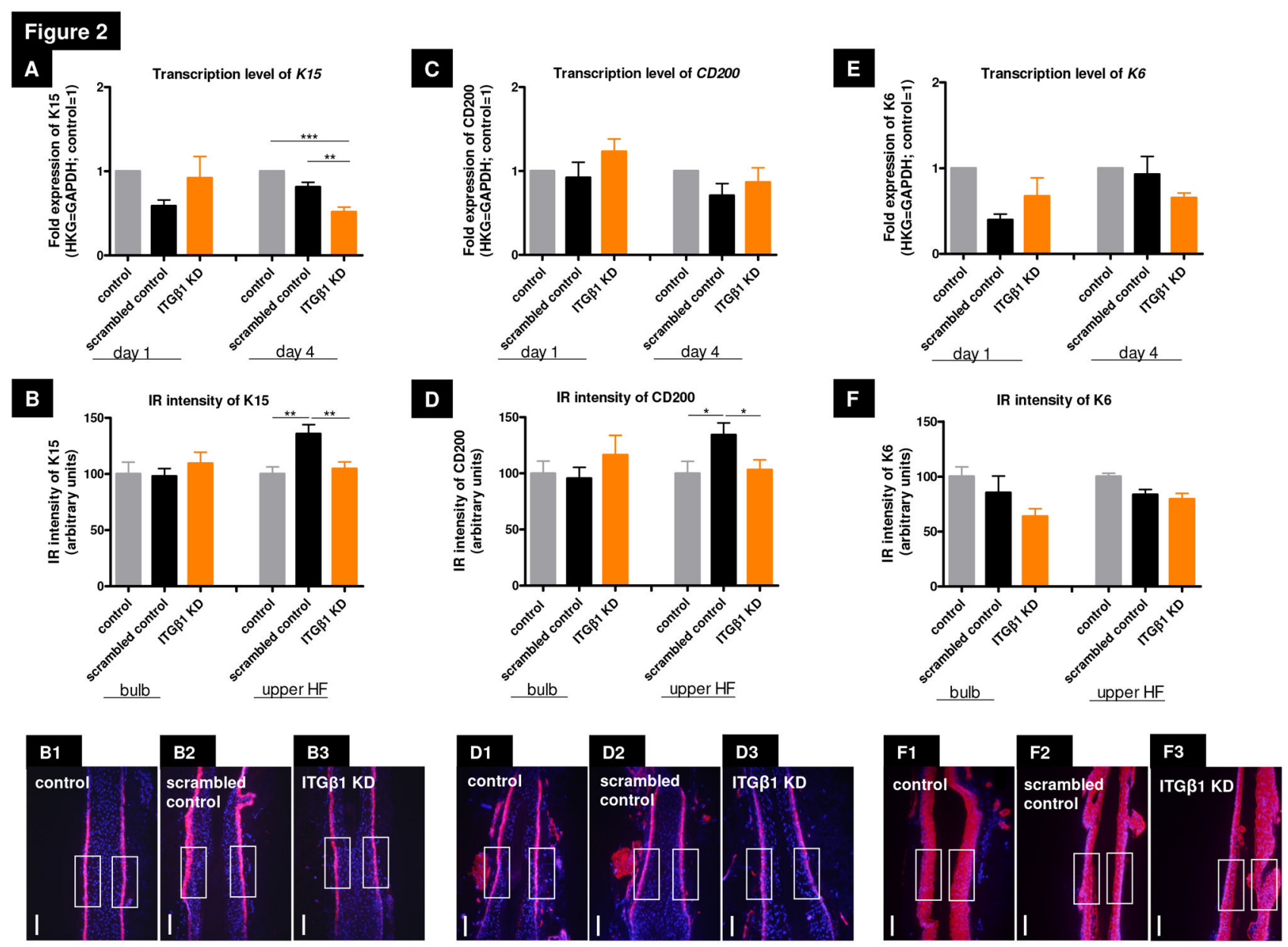

Figure 2. $\beta 1$ integrin silencing reduced significantly the epithelial progenitor protein expression in the hair follicle bulge. (A) Keratin 15 (K15) transcription was significantly reduced at day 4 by $\beta 1$ integrin siRNA compared to the scrambled control. (B) K15 immunoreactivity (IR) was most downregulated in $\beta 1$ integrin siRNA silenced HFs in the upper HF (including the bulge region), $n=19-26 \mathrm{HFs}$ of 3 individuals. (B1-3) Representative photos demonstrating the reference areas in the upper HF. (C) $\beta 1$ integrin silencing slightly enhanced the gene expression of CD200. (D) CD200 IR in the HF bulge was significantly reduced compared to the scrambled control at day $4 ; n=17-28$ HFs of 3 individuals. (D1-3) Representative photos which show the reference areas in the upper HF. (E) $\beta 1$ integrin knock down initially enhanced expression of $K 6$, but reduced the transcription level subsequently at day 4. (F) IR intensity of K6 in the different HF compartments. It demonstrated a non-specific repression of K6 IR in every analyzed HF compartment by the silencing procedure as such, but not specifically by $\beta 1$ integrin silencing. $n=16-18 \mathrm{HFs}$ of 2 individuals. (F1-3) Representative photos which show the reference areas in the upper HF. Fold expression of all analyzed genes were normalized to GAPDH. n=2-3 individuals (for RNA extraction $12 \mathrm{HFs} /$ patient were used and cultured over 4 days). IR intensity of the HF bulb and the upper HF was measured with a specified rectangle with ImageJ (250x125). White scale bars represent $=100 \mu \mathrm{m}$. All statistical analyses were performed with the one-way ANOVA by appropriate post hoc comparison (depending on a given Gaussian distribution), mean of normalized data $+/$ - SEM $\left({ }^{*} p<0.05,{ }^{* *} p<0.01,{ }^{* * *} p<0.001\right)$. Abbreviation: HKG=housekeeping gene, GAPDH=glyceraldehyde 3-phosphate dehydrogenase, ITG $\beta 1 \mathrm{KD}=\mathrm{knock}$ down of $\beta 1$ integrin, $\mathrm{K}=\mathrm{keratin}$, $\mathrm{IR}=$ immunoreactivity.

doi: 10.1371/journal.pone.0084356.g002

mimicking aECM was compared with standard organ-cultured, but also dispase-pretreated HFs, removal of the BM and CTS promoted epithelial cell apoptosis in the human HF epithelium in situ. The contact of dispase-pretreated HFs with the aECM alone already significantly reduced apoptosis and up-regulated proliferation of the HF epithelium (Figure 3C,D). Notably, the number of proliferating cells in the upper HF epithelium was 3 times higher than in the HF bulb. This suggests that the composition of aECM activated the outside-in signaling mediated by $\beta 1$ integrin and thus prolonged survival of the embedded HF epithelium; moreover, this enhanced the 


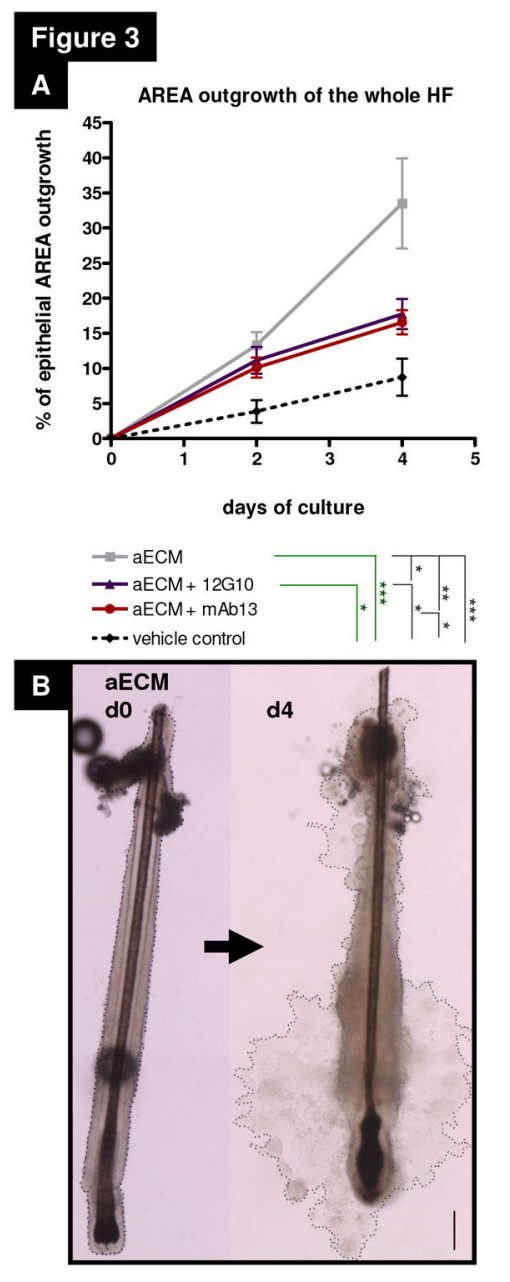

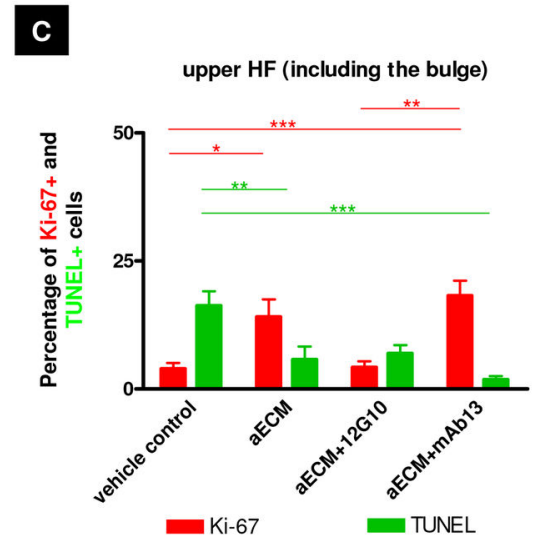

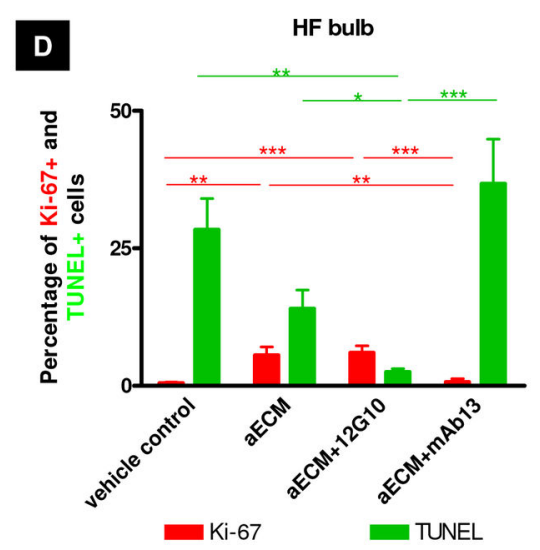

E Cortactin-activated sites in aECM embedded HFs

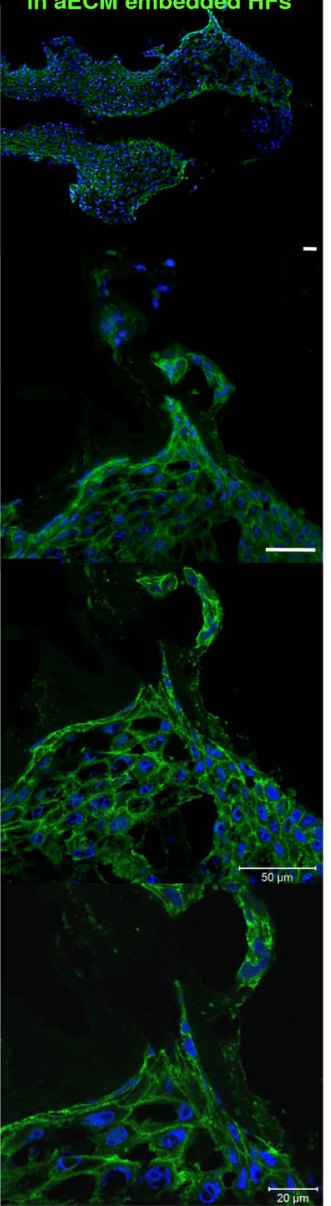

Figure 3. $\quad \beta 1$ integrin receptor ligands differentially regulate vitality of keratinocytes in different hair follicle compartments. (A) Epithelial outgrowth area of outer root sheath keratinocytes (ORSKs) over 4 days was measured. While the vehicle control hair follicles (HFs) showed no ORSK outgrowth in the culture dishes, the embedded HFs (aECM) showed a $30 \%$ larger ORSK outgrowth area. Activating and inhibiting $\beta 1$ integrin antibodies had very similar stimulatory effects on ORSK outgrowth area. $n=20-41 \mathrm{HFs}$ of 3-4 individuals. Green lines and stars mark the significances of day2; black lines and stars mark the significances of day4. Statistical analysis was performed with the Mann-Whitney test; mean+/-SEM $\left({ }^{*} p<0.05,{ }^{* *} p<0.01,{ }^{* * *} p<0.001\right)$. (B) Representative photos of dispase-treated, embedded HF (aECM). Dotted line demarcates the area of analysis for the ORSK outgrowth over the culture period of 4 days. Black scale bar=100 $\mu$ m. (C) Ki-67/TUNEL-staining demonstrated that $\beta 1$ integrin ligands, like extracellular matrix components and the specific receptor antibodies, decreased apoptosis in the upper HF, whereas in the $\mathrm{aECM}$ and $\mathrm{aECM}+\mathrm{mAb} 13$-treated group the proliferation rate is up-regulated, $\mathrm{aECM}+12 \mathrm{G} 10$ is similar to the vehicle control in the HF bulb. $n=7-15$ HFs of 2-3 individuals. (D) Ki-67/TUNEL-staining confirmed the influence of $\beta 1$ integrin ligands on HF bulb cells. In the aECM and $\mathrm{aECM}+12 \mathrm{G} 10$-treated group the number of proliferative cells in the human HF bulb significantly increased. The inhibiting antibody mAb13 enlarged apoptosis in HF bulb cells. n=8-16 HFs of 2-3 individuals. Statistical analyses of Ki-67/ TUNEL were performed with the one-way ANOVA by appropriate post hoc comparison (depending on a given Gaussian distribution), error bars=mean of normalized data $+/$ - SEM $\left({ }^{*} p<0.05,{ }^{* *} p<0.01,{ }^{* *} p<0.001\right)$. Red bars $=K i-67$, green bars $=$ TUNEL. (E) Cortactin revealed activated migration mainly in the HF bulb of the aECM-treated group. White scale bars $=50 \mu \mathrm{m}$. Abbreviation:

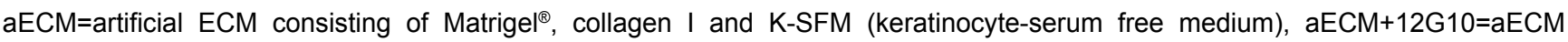
supplemented with the activating $\beta 1$ integrin antibody $12 \mathrm{G} 10, \mathrm{aECM}+\mathrm{mAb} 13=\mathrm{aECM}$ supplemented with the inhibiting $\beta 1$ integrin antibody mAb13.

doi: 10.1371/journal.pone.0084356.g003 


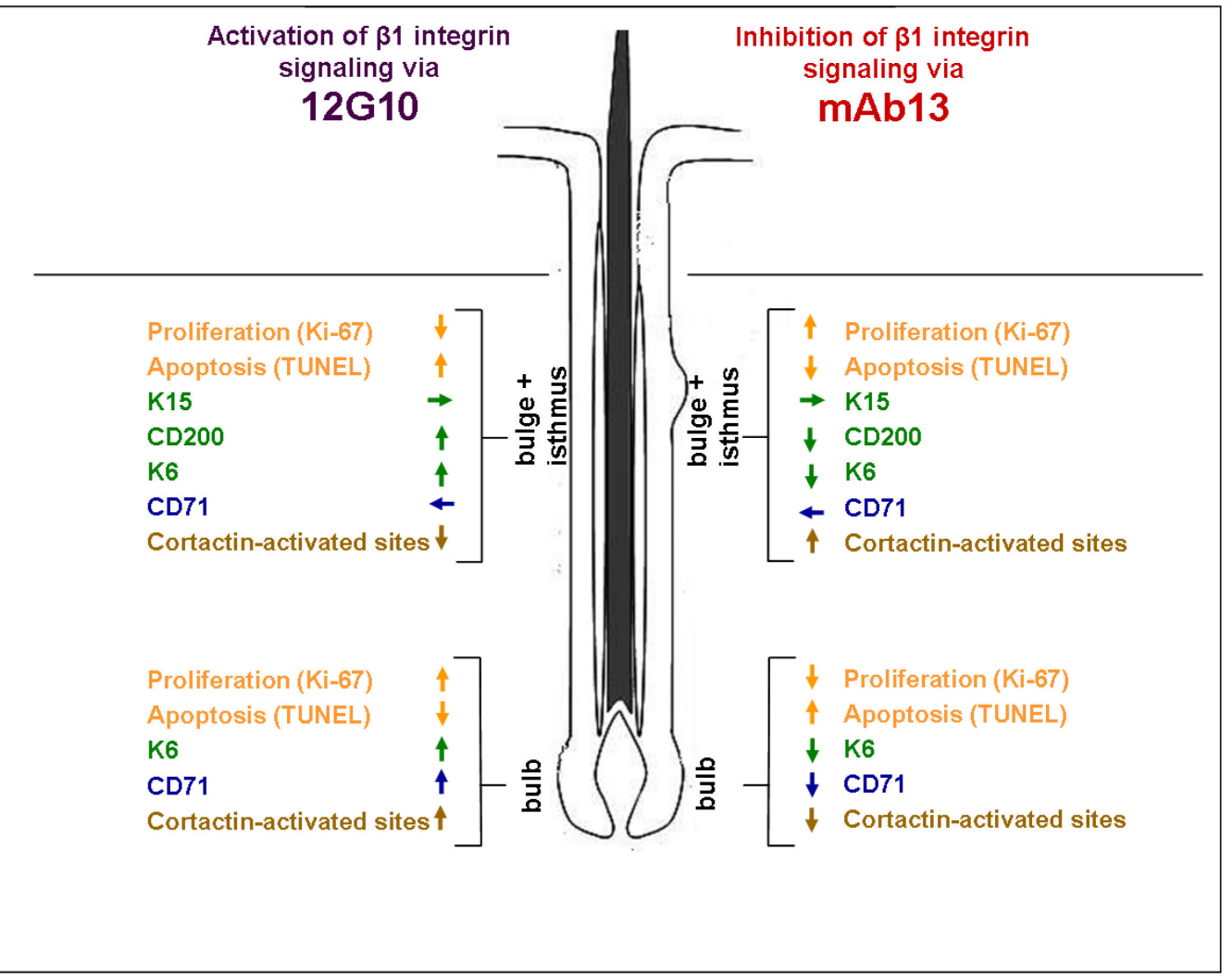

Figure 4. Schematic drawing for differential regulation via $\boldsymbol{\beta} 1$ integrin antibodies. Comparison of the influences of activated and inhibited signaling via $\beta 1$ integrin specific antibodies on the protein expression of different immunoreactivity markers. The immunoreactivity analyses of the $\beta 1$ integrin-activating (12G10) or -inhibiting (mAb13) antibody-treated and aECM (artificial extracellular matrix medium) embedded hair follicle (HF) epithelium suggested a different response of the epithelial progenitors cell subpopulations on $\beta 1$ integrin signaling. The application of aECM-incorporated $\beta 1$ integrin antibodies allowed distinguishing adult human epithelial progenitor cell subpopulations with distinct amplifying capacities in situ, which are located in separate epithelial compartments of human scalp HFs.

doi: 10.1371/journal.pone.0084356.g004

proliferation rate in the HF bulge, the SC-rich and slow-cycling HF compartment.

Testing, next, the effects of $\beta 1$ integrin antibodies incorporated into aECM showed that the $\beta 1$ integrin-stimulatory antibody (12G10) significantly reduced apoptosis in the HF bulb, and reduced proliferation in the upper HF compared to the aECM group (Figure $\mathbf{3 C , D}$ ). Instead, the $\beta 1$ integrininhibitory antibody (mAb13) had the opposite effect and upregulated apoptosis, yet only in the hair bulb; unexpectedly, it induced proliferation in the upper HF compartments including the bulge (Figure 3C,D, Figure 4). These antibody stimulation experiments suggest that distinct human ePCs in the HF show a differential proliferation/apoptosis response in situ to ß1 integrin-mediated signaling.
The extracellular matrix environment stimulates hair follicle keratinocyte migration primarily in the hair bulb

Besides proliferation and apoptosis, ORSK outgrowth is likely to be dominated by ORSK migration events. This was gauged by cortactin immunohistomorphometry, since activated cortactin accumulates in actin-enriched lamellipodia and membrane ruffles at the moving edge of migrating epithelial cells, signifying a role in actin network formation [69].

The hair bulbs of dispase-pretreated and subsequently aECM-embedded HFs showed strong activated cortactin IR, which was prominently expressed in a larger number of FA-like structures [70]. ORSKs showed enhanced migration into the provided aECM. This may explain why the largest outgrowth of ORSKs was measured around the HF bulb (Figure 3E) 
although the highest proliferative $\left(\mathrm{Ki}-67^{+}\right)$capacity of ORSKs was mainly seen in the upper HF (Figure $3 \mathbf{C}$ ). Therefore, the massive ORSK outgrowth seen in our CTS- and BM- mimicking ECM system likely also enhanced ORSK migration in the presence of $ß 1$ integrin ligands.

\section{Different human epithelial progenitor cell populations differ in their dependence on $\beta 1$ integrin signaling in situ}

To probe, next, whether $\beta 1$ integrin-mediated signaling is really needed for the maintenance and differentiation of ePCs we checked the effects of $\beta 1$ integrin knock down on the expression of ePC markers K15 and CD200 [16,47,54,71] were analyzed on the gene and protein expression level (Figure S1A-F). For qRT-PCR the entire dispase-pretreated, embedded and cultured HF epithelium was used. The upper HF including the bulge showed that the HF-ECM mimicking system significantly down-regulated the expression of the ePC markers K15 and CD200 on the gene and protein level in contrast to the vehicle control (dispase-pretreated HF epithelium cultured without Matrige ${ }^{\circledR} /$ collagen I) (Figure S1A,B,D,E).

The dispase-pretreated HF epithelium embedded in aECM or embedded and 12G10-treated showed a reduction of the transcription level of $K 6$ (Figure S1C), while the K6 IR pattern demonstrated a strong differentiation-inducing capacity in the whole HF epithelium (Figure S1F). Opposite results with regard to K6 qRT-PCR and IR were obtained for the standard denuded HF epithelium (vehicle control) compared to denuded, aECM embedded and mAb13-treated HFs (Figure S1C,F). Thus, although our CTS- and BM- mimicking ECM components, which are expected to mimic endogenous $\beta 1$ integrin ligands, optimize the survival of HF epithelium, the same ligands reduce the ePC reservoir in the human HF bulge and push this rapidly proliferating compartment of the HF epithelium towards differentiation, as indicated by increased $\mathrm{K} 6$ protein expression.

\section{Inhibiting or activating $\beta 1$ integrin signaling differentially stimulates human epithelial progenitor cells and their progeny in distinct hair follicle compartments}

Since this had never been tested before in human epithelium in situ, we also wanted to examine if anti-integrin antibodies impact on $\beta 1$ integrin transcription in adult human scalp HFs in situ. qRT-PCR showed that the aECM-incorporated stimulatory $\beta 1$ integrin antibody (12G10) demonstrated no further upregulation on day 4 in comparison to the aECM group (Figure 5A). Instead, the inhibitory mAb13 antibody downregulated $\beta 1$ integrin gene expression in human HFs in situ (Figure 5A). This is the first demonstration of a direct transcriptional effect of the inhibitory antibody on $\beta 1$ integrin gene expression in a human mini-organ.

Next, we tested whether distinct subpopulations of human ePCs and their progeny in situ showed a differential response pattern to the stimulation with antibodies that either stimulate or inhibit ß1 integrin-mediated signaling [29,72-74]. Indeed, this was the case. While the whole area outgrowth measurements of the HFs did not show stimulatory or inhibitory differences (Figure 3A), the proliferation and apoptosis analyses demonstrated significant differences in the HF bulb and the upper HF (Figure 3C,D). This was confirmed by corresponding differences in ORSK largest outgrowth in these two defined HF compartments (Figure 5C,D). While the ß1 integrin activating antibody 12G10 enhanced ORSK largest outgrowth mainly in the HF bulb (Figure 5D), interestingly and unexpectedly, in the upper HF (including the bulge), epithelial cell largest outgrowth was stimulated by the inhibitory antibody mAb13 (Figure 5C). Moreover, studying expression of CD71 the activating antibody $12 \mathrm{G} 10$, but not the inhibitory mAb13, significantly enhanced CD71 IR (and thus the number of transit amplifying cells) in human HF bulbs (Figure 5B; see also Figure 4 and Text S2). This suggests, dependent on the analysis method (area or largest outgrowth) that inhibiting or activating $\beta 1$ integrin signaling elicits differential responses in adult human HF ePCs compared to their more committed epithelial progeny.

\section{QLT0267 impacts on $\beta 1$ integrin-mediated signaling in human hair follicle epithelium}

As a first step towards dissecting the mechanisms by which B1 integrin-mediated signaling impacts on human ePCs and their progeny in situ, we used the putative ILK inhibitor QLT0267 [38,43] to probe the role of ILK. This cytoplasmic adaptor protein of $B 1$ and $B 3$ integrin plays a key role in many B1 integrin-mediated cellular processes, including actin rearrangement, cell adhesion, migration, proliferation, apoptosis and differentiation by associating with different regulatory proteins [40,75-78]. Since ILK protein expression has not yet been demonstrated in human HFs, this was first tested by Western blot. Indeed, human dispase-pretreated HF epithelium expressed ILK protein as the expected 53kDa band (Figure 6A).

Using QLT0267, we examined whether blocking ILK affected human HFs in situ, focussing on ORSK survival and migration. HF epithelium was embedded in aECM, supplemented with

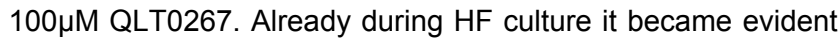
that approximately $40 \%$ of the aECM-embedded and QLT0267treated HFs lost their adhesion to the Matrige ${ }^{\circledR} /$ collagen milieu after 4 days of culture, a first overt evidence for massively reduced ILK activity to create FAs. The reduction of ILK expression via QLT0267 $(100 \mu \mathrm{M})$ was further documented by analyzing ILK protein IR at day 4. Both in the HF bulb and in the upper HF QLT0267 induced a significant reduction of ILK IR (by 60-70\%) (Figure 6D). Already 2 hours after QLT0267 incubation, the isolated HFs demonstrated a slightly reduction in ILK IR (Figure S2D).

Furthermore, QLT0267 treatment also induced substantial HF dystrophy, and almost abolished both ORSK outgrowth (Figure 6B,C) as well as cortactin-activated migration (Figure S3). This demonstrated that human ORSK migration in situ and F-actin cytoskeleton remodelling [77] critically depend on ILKmediated signaling via a Src activation of proteins like cortactin, which is mandatory for their phosphorylation and thereby for actin assembly [79].

Moreover, DAPI staining revealed numerous pyknotic nuclei in the HF epithelium indicating the high level of HF dystrophy 

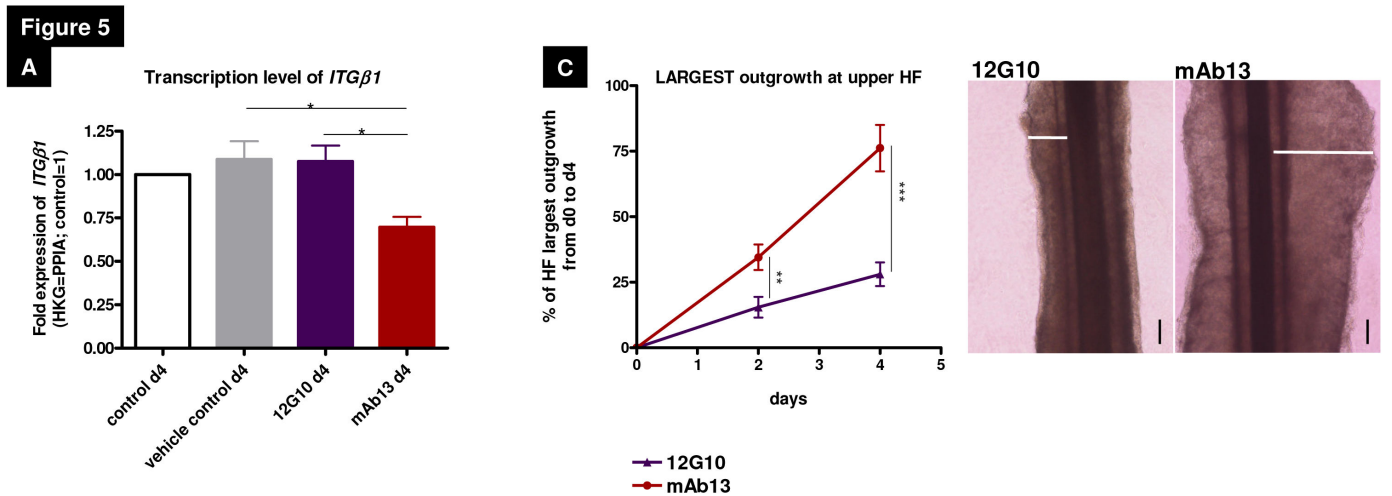

B

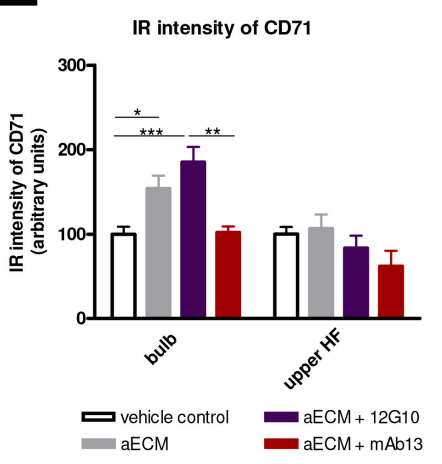

D
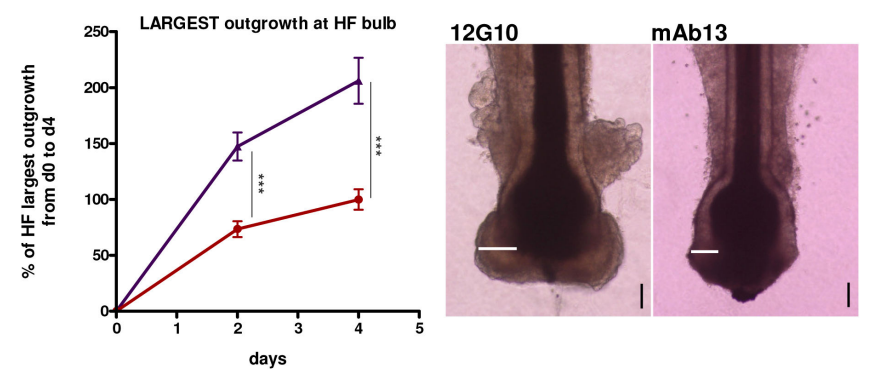

Figure 5. $\quad \beta 1$ integrin-mediated signaling stimulated different epithelial progenitor cell populations in distinct hair follicle compartments. (A) Relative gene expression of $\beta 1$ integrin. The $\beta 1$ integrin-activating antibody $12 \mathrm{G} 10$ did not alter $\beta 1$ integrin gene expression, whereas the inhibition of the receptor via mAb13 significantly reduced $\beta 1$ integrin expression. $n=1-2$ individuals in experimental triplicates (15 hair follicles [HFs]). (B) Immunoreactivity of CD71 enabled to distinguish between different epithelial progenitor cell populations within the HF bulge and the HF bulb. $n=5-10 \mathrm{HFs}$ of 3-4 individuals. The data were analysed by using the one-way ANOVA with the appropriate post hoc comparison (depending on a given Gaussian distribution), mean of normalized data $+/-$ SEM $\left({ }^{*} p<0.05,{ }^{* *} p<0.01,{ }^{* * *} p<0.001\right)$. (C) Measurement of the largest outgrowth in the upper HF and (D) HF bulb over 4 days displayed the large influence of the $\beta 1$ integrin antibody treatment and distinguished between the different epithelial progenitor cell populations via their response to $\beta 1$ integrin antibody stimulation. In the upper HF region (including the bulge) the inhibiting $\beta 1$ integrin antibody mAb13 significantly stimulated epithelial outgrowth, whereas in the HF bulb the activating antibody $12 \mathrm{G} 10$ antibody stimulated epithelial outgrowth. Photos show dispase-pretreated upper HFs and HF bulbs after embedding into the aECM (artificial extracellular matrix) system and treating with $\beta 1$ integrin antibodies at day 4 . White lines demarcate the reference areas. $n=18-33$ HFs of 4 individuals. Mean+/-SEM, using unpaired t-test $\left({ }^{*} p<0.05,{ }^{* *} p<0.01,{ }^{* *} p<0.001\right)$. Scale bars: $100 \mu m$. Abbreviation:

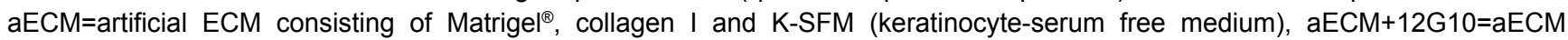
supplemented with the activating $\beta 1$ integrin antibody $12 \mathrm{G} 10, a E C M+m A b 13=a E C M$ supplemented with the inhibiting $\beta 1$ integrin antibody mAb13, HKG=housekeeping gene, PPIA=peptidylprolyl isomerase A, IR = immunoreactivity.

doi: 10.1371/journal.pone.0084356.g005

and apoptosis induced by QLT0267 treatment (data not shown). This was confirmed by quantitative immunohistomorphometry for cleaved caspase 3 (Figure 6E), TUNEL and Ki-67, which documented massive intraepithelial apoptosis and cessation of ORSK proliferation (Figure S2E). Therefore, pharmacological inhibition of ILK likely induced anoikis, i.e. cell death due to a loss of connection with the ECM or adjacent cells $[80,81]$, thereby destroying the entire ORS.

In summary, our studies provide the first evidence in a human complex system that ILK-dependent $\beta 1$ integrinmediated signaling is mandatory for the adhesion of basal layer
ORSK to the ECM thus stabilizing cell-ECM connection via FAs as well as promoting survival of human HF epithelium.

\section{Discussion}

Most data on the function of $\beta 1$ integrin-mediated signaling in ePCs and their interaction with the ECM are based on murine models [82-85] or cell culture experiments [66,86,87]. However, the role of $\beta 1$ integrin-mediated signaling in human ePCs growing within their natural tissue habitat had been largely unknown. Using organ-cultured human scalp HFs as a clinically relevant model for studying human ePCs in situ, we 

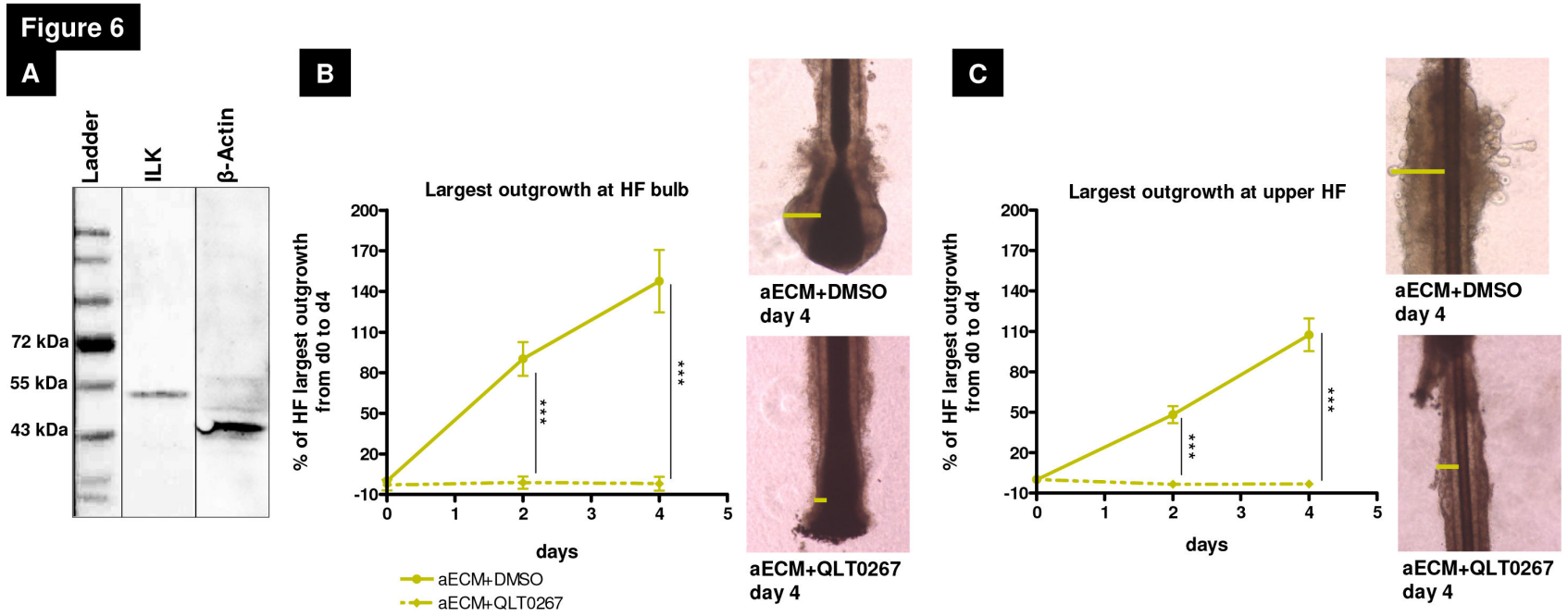

D

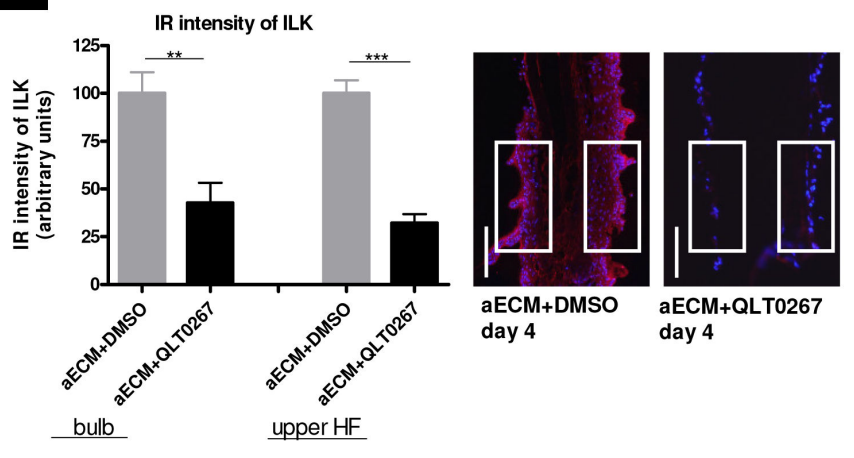

E

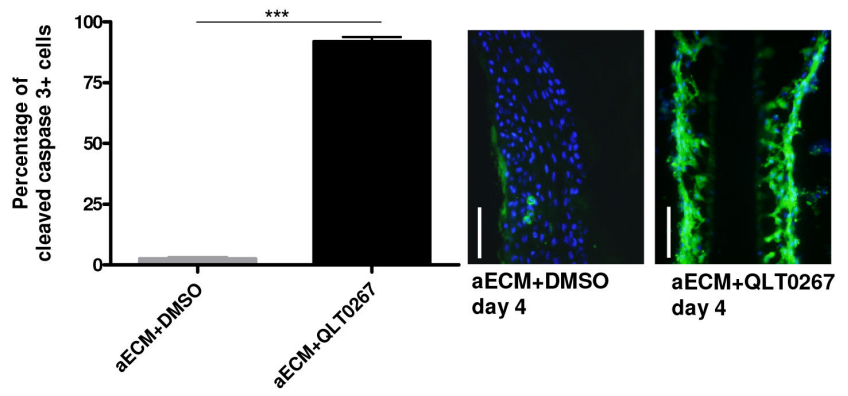

Figure 6. Integrin-linked kinase inhibition via QLT0267 stops the epithelial outgrowth. (A) Integrin-linked kinase (ILK) is expressed in human dispase-pretreated HF (hair follicle) keratinocytes, which was demonstrated by using the Western blot method in comparison to the protein expression of $\beta$-actin. (B) The analysis of the largest outgrowth in the HF bulb and (C) in the upper HF revealed the strong inhibitory effect of the pharmacological substance QLT0267 for the proliferative and migrative capacity. Representative photos. $n=24-28 \mathrm{HFs}$ of 3 individuals. (D) In the HF bulb and in the upper HF a significant reduction of ILK immunoreactivity could be demonstrated with QLT0267 treatment in comparison to our control HFs, which were dispase-pretreated and embedded in the artificial extracellular matrix with DMSO. Representative photos show the reference areas in the upper HF, n=7-10 HFs of 3 individuals. (E) The QLT0267 treatment caused a tremendous apoptotic effect in the HF epithelium, showing by nearly $100 \%$ cleaved caspase $3+$ outer root sheath keratinocytes. $n=5-10$ HFs of 3 individuals. For each immunoreactivity intensity analysis the control was normalized to $100 \%$. White scale bars $=50 \mu \mathrm{m}$. All statistical analyses were done by using Mann-Whitney test, $\left({ }^{*} p<0.05,{ }^{* *} p<0.01,{ }^{* * *} p<0.001\right)$; mean+/-SEM. Abbreviation: aECM+DMSO=artificial ECM consisting of Matrigel $\circledast$, collagen I and K-SFM (keratinocyte-serum free medium), aECM+QLT0267=aECM supplemented with the $100 \mu \mathrm{M}$ pharmacological inhibitor QLT0267, DMSO=Dimethyl sulfoxide, ILK=integrin-linked kinase, IR=immunoreactivity.

doi: 10.1371/journal.pone.0084356.g006

show here that $\beta 1$ integrin signaling controls survival, adhesion, and migration in distinct ORS populations, including human HF eSCs and their progeny. Moreover, our data suggest that $B 1$ integrin signaling is fundamental for maintenance of the HF bulge eSC niche, while different human HF ePC subpopulations differ in their response to $B 1$ integrin signaling. The examined HF effects of $B 1$ integrin signaling are ILKdependent.
Though our method of siRNA $\beta 1$ integrin silencing was functionally effective and was documented on the mRNA level, we could not detect any change in the protein level 4 days after transfection. While the half-life of integrins on the surface of cultured human keratinocytes in vitro reportedly is about $12 \mathrm{~h}$ [88], their half-life in situ and in vivo is much longer. For example, in murine epidermis, $\beta 1$ integrin can still be detected in vivo 10 days after Cre activation and in some HFs $\beta 1$ integrin 
IR is even visible after $1-2$ weeks $[3,89]$. This likely explains the discrepancy of our mRNA and protein results after knock down.

That $\beta 1$ integrin might be needed as a niche receptor for regulating proliferation activity in distinct ePC populations in the $\mathrm{HF}$ bulb and bulge is in line with neonatal K5Cre $\beta 1$ null-mice showing HF and sebaceous gland loss, and greatly reduced proliferation [89]. The current silencing results also are in line with our previous finding that the stimulation of $B 1$ integrinmediated signaling enhances the proliferation of hair matrix keratinocytes in organ-cultured human HFs, using the ß1 integrin-activating antibody 12G10 [29].

$\mathrm{K} 15$ and CD200 are well accepted as ePC markers of the HF bulge $[16,20,23,54,90]$, but whether the expression of these markers is $ß 1$ integrin-dependent remains unclear. The current knock down data now clarify that $ß 1$ integrin signaling is necessary for keeping human ePCs in an undifferentiated state in situ, i.e. for maintenance of $\mathrm{K} 15^{+}$and $\mathrm{CD} 200^{+}$ORSKs in the HF bulge.

The role of $\beta 1$ integrin in the maintenance of eSCs or ePCs is still controversially discussed. Jones and Watt proposed a role of $\beta 1$ integrin signaling for the maintenance of human skin eSCs in vitro, because these cells expressed high levels of $\beta 1$ integrin and showed typical SC properties like high CFE [28]. In contrast, a direct link between the loss of $\beta 1$ integrin skinspecific conditional knock out to an ePC or eSC reduction could not be elucidated in mutant mice [84], and $B 1$ integrin protein levels in situ are not markedly higher in the human bulge than elsewhere in the human ORS [29]. However, here we show that $\beta 1$ integrin silencing impacts on K15 and CD200 expression in a complex human mini-organ, the HF suggesting that $\beta 1$ integrin-mediated signaling is indeed required for ePC maintenance in adult human HFs.

Since the human bulge likely represents an immunologically privileged SC niche [91], it is interesting that $ß 1$ integrin silencing also reduces HF bulge expression of the immunoinhibitory "no danger"-signal, CD200. Future functional experiments, therefore, will need to clarify whether this reduced CD200 expression compromises the relative HF bulge immune privilege in human HFs. Clinically, this may be relevant for irreversible forms of human hair loss characterized by a loss of $\mathrm{K} 15^{+} / \mathrm{CD} 200^{+}$bulge cells and a collapse of the HF bulge immune privilege [91], like the cicatricial alopecia, lichen planopilaris [61], where insufficient ß1 integrin-mediated signaling may contribute to the CD200-dependent component of the HF bulge immune privilege collapse demonstrated in this scarring hair loss disorder [91].

For the direct manipulation of $\beta 1$ integrin-mediated signaling in ePC populations of the HF epithelium removal of the HFs BM and CTS by dispase appeared necessary. This, however, artificially disrupts cell-ECM connections and greatly dysregulates the surrounding ECM environment, likely inducing a broad range of abnormalities [92]. Under our HF organ culture conditions, this unphysiological culture of denuded HF epithelium is further compounded by the absence of serum components such that may promote $ß 1$ integrin signaling, thus severely compromising the normal conditions for outgrowth and survival of the HF epithelium. To optimize this defective ECM

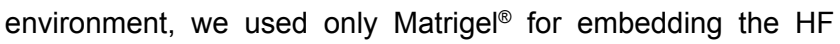

epithelium, guided by previous work [93]. However, after several days, most HFs lost their adhesion to the provided surrogate matrix. This might result from the activity of enzymes like matrix metalloproteinase (MMPs) which are expressed in HFs for degrading ECM components and by this contribute to HF growth and cycling [94,95]. But such enzymes require a physiological balance between their activity and their specific inhibitors for a controlled function [94]. Adding collagen I to

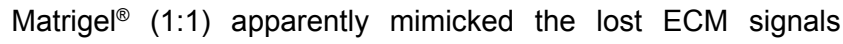
arisen from the HFs CTS and BM, and enabled human HF ORSK outgrowth in situ and ORSK emigration.

The opposite effects on proliferation and apoptosis in the HF bulb and bulge, but also the reduction of the ePC markers K15 and CD200 in these embedded HFs, confirm the widely appreciated effect of Matrige ${ }^{\circledR}$ as a stimulator of proliferation and differentiation [96]. Thus, this mouse sarcoma derived matrix is not an optimal surrogate of the HF ECM for mimicking the human SC niche in situ and for keeping human ePCs in an undifferentiated state. Therefore, better-defined human-derived alternative ECM composites are urgently needed [97,98].

Interestingly, inhibiting or activating $\beta 1$ integrin signaling modulates the functions of human ePCs and their progeny in a highly differential manner, depending on where these cells are located within the HF epithelium. This obvious difference could not be shown measuring the whole outgrowth area of the HF (Figure 3A) while the more specific analysis methods of the largest outgrowth and the proliferation/apoptosis of defined HF compartments (Figure 3C,D and Figure 5C,D), revealed the different antibody effects. These specific differences are possibly due to the functionally different cells types located in these compartments, namely ePCs in the HF bulge versus transit amplifying cells in the HF bulb. These findings also fit well to the analysis of the different proliferation and apoptosis potential in the bulb and the upper HF bulge.

The activating $\beta 1$ integrin antibody (12G10) induces proliferation and differentiation in the HF bulb whereas the inhibiting $\beta 1$ integrin antibody (mAb13) keeps the ePCs in a more undifferentiated state. But the opposite effects were shown on the more distal located HF compartment the upper HF including the bulge (see Figure $\mathbf{4}$ for details). Our results obtained with manipulating $\beta 1$ integrin activity via specific activating and inhibiting antibodies arose new functions for their usage and invite the hypothesis that $\beta 1$ integrin receptormediated signaling in HF matrix cells primarily regulates and stimulates the proliferative capacity and differentiation of the $\mathrm{HF}$. In contrast, $\beta 1$ integrin signaling in the eSC niche (HF bulge) appears to operate as quiescence signal by outside-in signaling via the surrounding ECM. By using the inhibiting antibody mAb13 this $\beta 1$ integrin-mediated signaling in the hair matrix cells was changed followed by a tremendous apoptosis, whereas the proliferation quiescence function in the HF bulge altered which lead to an increased $\mathrm{Ki}-67^{+}$cell number.

We postulate that the different antibodies are useful markers to distinguish between ePCs in the bulge and transit amplifying cells in the bulb, which are known to have different proliferation capacities. While the transit amplifying cells of the HF bulb are highly active cells for reproducing/maintenance the HF, the ePCs of the HF bulge represent a slow cycling and quiescent 
ORSK population. Changes of the $\beta 1$ integrin-mediated signaling in these HF compartments, for example by using of $m A b 13$, lead to a disturbed outside-in signaling reaction. Consequently, mAb13 pushed the proliferating active transit amplifying cells into apoptosis, while the slow-cycling ePCs in the HF bulge did not change their status of activity. This novel finding shows that using these specific $\beta 1$ integrin antibodies initiates different reactions of ePCs in the bulge and in the bulb. The manipulation of the $\beta 1$ integrin-mediated signaling certainly appears to be one of the means by which the surrounding ECM profoundly and differentially modulates epithelial cell behavior in human HFs.

The manipulation of the $\beta 1$ integrin-mediated signaling certainly appears to be one of the means by which the surrounding ECM profoundly and differentially modulates epithelial cell behavior in human HFs.

It is controversially debated whether ILK really is a true kinase or just a scaffolding protein [76,99-102] and it has been questioned how the pharmacological inhibitor QLT0267 really works, which was developed to inhibit ATP binding of ILK [44]. Until now the role of ILK in cellular processes has been studied in transformed and/or tumorigenic cells [37,38,103], and in mouse models $[39,78,104]$, but not in a complex human miniorgan. By using our experimental setup an efficient reduction of ILK expression in situ via QLT0276, the potent apoptosisinducing capacity $[37,38]$ and the loss of adhesion (abrogates ORSK migration) was striking in pharmacologically ILKblockaded human HFs (Figure 6, Figure S2E). Former studies with this pharmacological inhibitor also demonstrated an effective reduction of ILK activity as well as a decrease of AKT (AKT kinase) and FAK (focal adhesion kinase) phosphorylation in tumor cell lines $[36,38,44]$.

Importantly, our human HF organ culture data are in line with the results obtained in ILK-K5 knock out mice concerning the impaired directional migration followed by a missing forming of stable lamellipodia-like structures, as well as the detachment through the surrounding environment [105]. Thus, the high level of ORSK apoptosis could be caused by missing AKT phosphorylation after QLT0267 treatment, as previously described in a tumor cell line [41] or the impaired formation of FA because of a reduced ILK expression [106,107]. Irrespective of this consideration, our data suggest that ILK protein is functionally important for $\beta 1$ integrin-mediated signaling in the human HF and for the survival of human ORSKs.

Taken together, our study demonstrates that ePCs in human HFs require $\beta 1$ integrin-mediated signaling for survival, adhesion, and migration, and that different human HF ePC subpopulations differ in their response to $\beta 1$ integrin signaling. Mechanistically, this effect is likely ILK-dependent. These new insights into the $\beta 1$ integrin-dependence of distinct human ePC populations enrich our as yet very fragmentary understanding of the integrin-dependent topobiology of human ePCs in situ, and are relevant for cell-based regenerative medicine strategies that employ HF-derived ePCs $[90,108]$.

\section{Supporting Information}

Figure S1. Differentiation of epithelial progenitor cells is regulated by $\beta 1$ integrin ligands. (A) Embedding into the niche mimicking aECM (artificial extracellular matrix) system significantly downregulated the gene expression of the HF (hair follicle) progenitor marker Keratin 15 (K15). The $\beta 1$ integrin inhibiting antibody mAb13 increased the $K 15$ transcription.

(B) Embedding into the aECM system $\beta 1$ integrin antibodies significantly reduced the gene expression of CD200. (C) The Keratin 6 (K6) transcription was strongly repressed in the $\mathrm{aECM}$ and $\mathrm{aECM}+12 \mathrm{G} 10$-treated group, while this reduction is not so high in the mAb13-treated group. $n=1$ (2) individuals in experimental triplicates (12-15 HFs). (D) Immunoreactivity of K15 was only found in the upper HF including the bulge. By counting K15+ cells in a specified area $(250 \times 125)$ the decrease of this progenitor marker was measurable. $n=7-15$ HFs of 3-4 individuals. (E) CD200+ cells were also only found in the upper $\mathrm{HF}$ including the bulge. The CD200+ cells were counted in a specified area $(250 \times 125)$ and confirmed the gene expression results of this progenitor marker. $n=7-10 \mathrm{HFs}$ of 2-3 individuals. (F) The immunoreactivity expression pattern of $\mathrm{K} 6$ was analysed in the HF bulb, lower HF and upper HF by quantitative immunohistochemistry in fixed rectangle. The supplementation of the inhibitory antibody mAb13 reduced the differentiation inducing capacity of the artificial ECM system in the whole HF. $n=4-7 \mathrm{HFs}$ of 3 individuals. White scale bars in the representative photos $=100 \mu \mathrm{m}$. All data were analysed by using the One way ANOVA, Bonferroni post hoc test, mean +/SEM ( $\left.{ }^{*} p<0.05,{ }^{* *} p<0.01,{ }^{* * *} p<0.001\right)$. Abbreviation: $a E C M=$ artificial ECM consisting of Matrige ${ }^{\circledR}$, collagen I and K-SFM (keratinocyte-serum free medium), $a E C M+12 G 10=a E C M$ supplemented with the activating $\beta 1$ integrin antibody $12 \mathrm{G} 10$, $a E C M+m A b 13=a E C M$ supplemented with the inhibiting $\beta 1$ integrin antibody mAb13, HKG=housekeeping gene, PPIA=peptidylprolyl isomerase $\mathrm{A}$.

(TIF)

Figure S2. $\beta 1$ intergin knock down and the inhibition via QLT0267. (A) The knock down of $\beta 1$ integrin did not alter the CD71 immunoreactivity (IR) expression in the HFs. $n=11-18-$ HFs of 2 individuals. (B) MHC la IR intensity demonstrated that the silencing reaction and the specific knock down of ITG $\beta 1$ had no influence on the immune privilege of the HF bulge. $\mathrm{n}=12-19 \mathrm{HFs}$ of 2 individuals. (C) Representative photos of the EdU IR of scrambled control and ITG $\beta 1 \mathrm{KD}$ HFs are shown. (D) Intergin-linked kinase (ILK) IR intensity in human HFs after $2 \mathrm{~h}$ incubation in $37^{\circ} \mathrm{C}$ with or without QLT0267 before embedding into the artificial extracellular matrix demonstrated the fast reduction/inhibiton of ILK in outer root sheath keratinocytes. (E) Ki-67/TUNEL-staining confirmed the caspase 3 staining, while the QLT0267-treated HFs showed no proliferation, but a high apoptosis rate in comparison to the DMSO-treated control. Red bars=Ki-67, green bars=TUNEL. $\mathrm{n}=7-12 \mathrm{HFs}$ of 3 individuals. For each analysis of the IR intensity the control was normalized to $100 \%$. White scale bars $=50 \mu \mathrm{m}$. All statistical analyses were done by using MannWhitney test, $\left({ }^{* * *} p<0.001\right)$, mean $+/-$ SEM. Abbreviation: ITG $\beta 1$ 
ß1 Integrin Controls Epithelial Progenitor Cells

$\mathrm{KD}=\beta 1$ integrin knock down, $\mathrm{MHC}$ la $=$ major histocompatibility complex (MHC) class la.

(TIF)

Figure S3. Integrin-linked kinase inhibition via QLT0267 inhibits keratinocyte migration. The cortactin immunoreactivity was nearly absent in the aECM+QLT0267treated HFs compared to the aECM+DMSO-treated group on day 4. This demonstrated that human outer root sheath keratinocyte migration in situ and F-actin cytoskeleton remodelling [76] depend on integrin-linked kinase (ILK)mediated signalling via a Src (Proto-oncogene tyrosine-protein kinase) activation of proteins like cortactin. Abbreviation: aECM

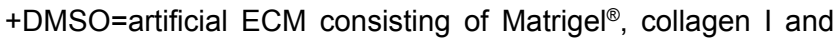
K-SFM (keratinocyte-serum free medium), aECM + QLT0267=aECM supplemented with the $100 \mu \mathrm{M}$ pharmacological inhibitor QLT0267, DMSO=Dimethyl sulfoxide. (TIF)

\section{References}

1. Benoit YD, Lussier C, Ducharme PA, Sivret S, Schnapp LM et al. (2009) Integrin alpha8beta1 regulates adhesion, migration and proliferation of human intestinal crypt cells via a predominant RhoA/ ROCK-dependent mechanism. Biol Cell 101: 695-708. doi:10.1042/ BC20090060. PubMed: 19527220.

2. Streuli CH (2009) Integrins and cell-fate determination. J Cell Sci 122: 171-177. doi:10.1242/jcs.018945. PubMed: 19118209.

3. Brakebusch C, Grose R, Quondamatteo F, Ramirez A, Jorcano JL et al. (2000) Skin and hair follicle integrity is crucially dependent on beta 1 integrin expression on keratinocytes. EMBO J 19: 3990-4003. doi: 10.1093/emboj/19.15.3990. PubMed: 10921880.

4. Hynes RO (2002) Integrins: bidirectional, allosteric signaling machines. Cell 110: 673-687. doi:10.1016/S0092-8674(02)00971-6. PubMed: 12297042

5. Campbell ID, Humphries MJ (2011) Integrin structure, activation, and interactions. Cold Spring Harb Perspect Biol 3.

6. Legate KR, Wickström SA, Fässler R (2009) Genetic and cell biological analysis of integrin outside-in signaling. Genes Dev 23: 397-418. doi: 10.1101/gad.1758709. PubMed: 19240129.

7. Byron A, Morgan MR, Humphries MJ (2010) Adhesion signalling complexes. Curr Biol 20: R1063-R1067. doi:10.1016/j.cub.2010.10.059. PubMed: 21172621.

8. Giancotti FG, Ruoslahti E (1999) Integrin signaling. Science 285: 1028-1032. doi:10.1126/science.285.5430.1028. PubMed: 10446041

9. Humphries MJ (2002) Insights into integrin-ligand binding and activation from the first crystal structure. Arthritis Res 4 Suppl 3: S69S78. doi:10.1186/ar563. PubMed: 12110125.

10. Huttenlocher A, Horwitz AR (2011) Integrins in cell migration. Cold Spring Harb Perspect Biol 3: a005074. PubMed: 21885598.

11. Meves A, Stremmel C, Thomas Bottcher R, Fassler R (2013) beta1 integrins with individually disrupted cytoplasmic NPxY motifs are embryonic lethal but partially active in epidermis. J Invest Dermatol.

12. Philp D, Chen SS, Fitzgerald W, Orenstein J, Margolis L et al. (2005) Complex extracellular matrices promote tissue-specific stem cell differentiation. Stem Cells 23: 288-296. doi:10.1634/stemcells. 2002-0109. PubMed: 15671151.

13. Chen S, Lewallen M, Xie T (2013) Adhesion in the stem cell niche: biological roles and regulation. Development 140: 255-265. PubMed: 23250203

14. Cotsarelis G, Kaur P, Dhouailly D, Hengge U, Bickenbach J (1999) Epithelial stem cells in the skin: definition, markers, localization and functions. Exp Dermatol 8: 80-88. doi:10.1111/j. 1600-0625.1999.tb00351.x. PubMed: 10206725.

15. Watt FM (2002) Role of integrins in regulating epidermal adhesion, growth and differentiation. EMBO J 21: 3919-3926. doi:10.1093/emboj/ cdf399. PubMed: 12145193.

16. Kloepper JE, Tiede S, Brinckmann J, Reinhardt DP, Meyer W et al. (2008) Immunophenotyping of the human bulge region: the quest to define useful in situ markers for human epithelial hair follicle stem cells
Text S1. (DOC)

Text S2. (DOC)

\section{Acknowledgements}

The authors gratefully acknowledge Dr. Moser, Berlin, and Dr. Funk, Munich, for generously providing human scalp skin samples for this study as well as the excellent professional supply and advice of the Humphries' Lab with $\beta 1$ integrin antibodies.

\section{Author Contributions}

Conceived and designed the experiments: NE ST RP JEK. Performed the experiments: NE AY TB. Analyzed the data: NE AY. Contributed reagents/materials/analysis tools: TB $\mathrm{MH}$. Wrote the manuscript: NE RP JEK AY ST TB MH.

and their niche. Exp Dermatol 17: 592-609. doi:10.1111/j. 1600-0625.2008.00720.x. PubMed: 18558994.

17. Roh C, Tao Q, Photopoulos C, Lyle S (2005) In vitro differences between keratinocyte stem cells and transit-amplifying cells of the human hair follicle. J Invest Dermatol 125: 1099-1105. doi:10.1111/j. 0022-202X.2005.23958.x. PubMed: 16354178.

18. Morris RJ, Liu Y, Marles L, Yang Z, Trempus C et al. (2004) Capturing and profiling adult hair follicle stem cells. Nat Biotechnol 22: 411-417. doi:10.1038/nbt950. PubMed: 15024388.

19. Tiede S, Kloepper JE, Bodò E, Tiwari S, Kruse C et al. (2007) Hair follicle stem cells: walking the maze. Eur J Cell Biol 86: 355-376. doi: 10.1016/j.ejcb.2007.03.006. PubMed: 17576022

20. Fujiwara H, Ferreira M, Donati G, Marciano DK, Linton JM et al. (2011) The basement membrane of hair follicle stem cells is a muscle cell niche. Cell 144: 577-589. doi:10.1016/j.cell.2011.01.014. PubMed: 21335239

21. Meyer KC, Klatte JE, Dinh HV, Harries MJ, Reithmayer K et al. (2008) Evidence that the bulge region is a site of relative immune privilege in human hair follicles. $\mathrm{Br} \mathrm{J}$ Dermatol 159: 1077-1085. PubMed: 18795933

22. Lavker RM, Sun TT (2000) Epidermal stem cells: properties, markers, and location. Proc Natl Acad Sci U S A 97: 13473-13475. doi:10.1073/ pnas.250380097. PubMed: 11087834

23. Cotsarelis G, Sun TT, Lavker RM (1990) Label-retaining cells reside in the bulge area of pilosebaceous unit: implications for follicular stem cells, hair cycle, and skin carcinogenesis. Cell 61: 1329-1337. doi: 10.1016/0092-8674(90)90696-C. PubMed: 2364430.

24. Lyle S, Christofidou-Solomidou M, Liu Y, Elder DE, Albelda S et al. (1998) The C8/144B monoclonal antibody recognizes cytokeratin 15 and defines the location of human hair follicle stem cells. J Cell Sci 111 (21): 3179-3188. PubMed: 9763512.

25. Webb A, Li A, Kaur P (2004) Location and phenotype of human adult keratinocyte stem cells of the skin. Differentiation 72: 387-395. doi: 10.1111/j.1432-0436.2004.07208005.x. PubMed: 15606498

26. Beck B, Blanpain C (2012) Mechanisms regulating epidermal stem cells. EMBO J 31: 2067-2075. doi:10.1038/emboj.2012.67. PubMed: 22433839.

27. Inoue K, Aoi N, Sato T, Yamauchi Y, Suga H et al. (2009) Differential expression of stem-cell-associated markers in human hair follicle epithelial cells. Lab Invest 89: 844-856. doi:10.1038/labinvest.2009.48. PubMed: 19506554

28. Jones PH, Watt FM (1993) Separation of human epidermal stem cells from transit amplifying cells on the basis of differences in integrin function and expression. Cell 73: 713-724. doi: 10.1016/0092-8674(93)90251-K. PubMed: 8500165.

29. Kloepper JE, Hendrix S, Bodó E, Tiede S, Humphries MJ et al. (2008) Functional role of beta 1 integrin-mediated signalling in the human hair follicle. Exp Cell Res 314: 498-508. doi:10.1016/j.yexcr.2007.10.030. PubMed: 18155697 
30. Gilcrease $M Z$ (2007) Integrin signaling in epithelial cells. Cancer Lett 247: 1-25. doi:10.1016/j.canlet.2006.03.031. PubMed: 16725254

31. Commo S, Bernard BA (1997) The distribution of alpha 2 beta 1, alpha 3 beta 1 and alpha 6 beta 4 integrins identifies distinct subpopulations of basal keratinocytes in the outer root sheath of the human anagen hair follicle. Cell Mol Life Sci 53: 466-471. doi:10.1007/s000180050057. PubMed: 9176567

32. Margadant C, Charafeddine RA, Sonnenberg A (2010) Unique and redundant functions of integrins in the epidermis. FASEB $\mathrm{J} 24$ : 4133-4152. doi:10.1096/fj.09-151449. PubMed: 20624931.

33. Schneider MR, Schmidt-Ullrich R, Paus R (2009) The hair follicle as a dynamic miniorgan. Curr Biol 19: R132-R142. doi:10.1016/j.cub. 2008.12.005. PubMed: 19211055.

34. Kloepper JE, Sugawara K, Al-Nuaimi Y, Gáspár E, van Beek N et al. (2010) Methods in hair research: how to objectively distinguish between anagen and catagen in human hair follicle organ culture. Exp Dermatol 19: 305-312. PubMed: 19725870.

35. Villa-Diaz LG, Ross AM, Lahann J, Krebsbach PH (2013) Concise Review: The Evolution of human pluripotent stem cell culture: From feeder cells to synthetic coatings. Stem Cells 31: 1-7. PubMed: 23081828.

36. Kalra J, Warburton C, Fang K, Edwards L, Daynard T et al. (2009) QLT0267, a small molecule inhibitor targeting integrin-linked kinase (ILK), and docetaxel can combine to produce synergistic interactions linked to enhanced cytotoxicity, reductions in P-AKT levels, altered Factin architecture and improved treatment outcomes in an orthotopic breast cancer model. Breast Cancer Res 11: R25. doi:10.1186/ bcr2395. PubMed: 19409087.

37. Lim S, Kawamura E, Fielding AB, Maydan M, Dedhar S (2013) Integrinlinked kinase regulates interphase and mitotic microtubule dynamics. PLOS ONE 8: e53702. doi:10.1371/journal.pone.0053702. PubMed: 23349730 .

38. Eke I, Leonhardt F, Storch K, Hehlgans S, Cordes N (2009) The small molecule inhibitor QLT0267 Radiosensitizes squamous cell carcinoma cells of the head and neck. PLOS ONE 4: e6434. doi:10.1371/ journal.pone.0006434. PubMed: 19649326.

39. Lange A, Wickström SA, Jakobson M, Zent R, Sainio K et al. (2009) Integrin-linked kinase is an adaptor with essential functions during mouse development. Nature 461: 1002-1006. doi:10.1038/ nature08468. PubMed: 19829382

40. Leyme A, Bourd-Boittin K, Bonnier D, Falconer A, Arlot-Bonnemains $Y$ et al. (2012) Identification of ILK as a new partner of the ADAM12 disintegrin and metalloprotease in cell adhesion and survival. Mol Biol Cell 23: 3461-3472. doi:10.1091/mbc.E11-11-0918. PubMed: 22767580

41. Wickström SA, Radovanac K, Fässler R (2011) Genetic analyses of integrin signaling. Cold Spring Harb Perspect Biol 3: ([MedlinePgn:]) PubMed: 21421914

42. Philpott MP, Sanders D, Westgate GE, Kealey T (1994) Human hair growth in vitro: a model for the study of hair follicle biology. J Dermatol Sci 7 Suppl: S55-S72. doi:10.1016/0923-1811(94)90036-1. PubMed: 7999676.

43. Wang $X$, Zhang $Z$, Yao $C$ (2011) Targeting integrin-linked kinase increases apoptosis and decreases invasion of myeloma cell lines and inhibits IL-6 and VEGF secretion from BMSCs. Med Oncol 28: 1596-1600. PubMed: 20625942

44. Younes MN, Yigitbasi OG, Yazici YD, Jasser SA, Bucana CD et al. (2007) Effects of the integrin-linked kinase inhibitor QLT0267 on squamous cell carcinoma of the head and neck. Arch Otolaryngol Head Neck Surg 133: 15-23. doi:10.1001/archotol.133.1.15. PubMed: 17224516

45. Kotogány E, Dudits D, Horváth GV, Ayaydin F (2010) A rapid and robust assay for detection of S-phase cell cycle progression in plant cells and tissues by using ethynyl deoxyuridine. Plant Methods 6: 5 . doi:10.1186/1746-4811-6-5. PubMed: 20181034

46. Wang QQ, Zhang ZY, Xiao JY, Yi C, Li LZ et al. (2011) Knockdown of nucleophosmin induces S-phase arrest in HepG2 cells. Chin J Cancer 30: 853-860. doi:10.5732/cjc.011.10362. PubMed: 22098949

47. Tiede S, Koop N, Kloepper JE, Fässler R, Paus R (2009) Nonviral in situ green fluorescent protein labeling and culture of primary, adult human hair follicle epithelial progenitor cells. Stem Cells 27: 2793-2803. doi:10.1002/stem.213. PubMed: 19750535

48. Lyle S, Christofidou-Solomidou M, Liu Y, Elder DE, Albelda S et al. (1999) Human hair follicle bulge cells are biochemically distinct and possess an epithelial stem cell phenotype. J Investig Dermatol Symp Proc 4: 296-301. doi:10.1038/sj.jidsp.5640233. PubMed: 10674385.

49. Sugawara K, Biro T, Tsuruta D, Toth BI, Kromminga A, et al. (2012) Endocannabinoids limit excessive mast cell maturation and activation in human skin. J Allergy Clin Immunol 129: 726-738 e728
50. Samuelov L, Sprecher E, Tsuruta D, Bíró T, Kloepper JE et al. (2012) $P$-cadherin regulates human hair growth and cycling via canonical Wnt signaling and transforming growth factor-beta2. J Invest Dermatol 132: 2332-2341. doi:10.1038/jid.2012.171. PubMed: 22696062.

51. Watt FM, Jensen KB (2009) Epidermal stem cell diversity and quiescence. EMBO. Mol Med 1: 260-267.

52. Xu X, Lyle S, Liu Y, Solky B, Cotsarelis G (2003) Differential expression of cyclin D1 in the human hair follicle. Am J Pathol 163: 969-978. doi: 10.1016/S0002-9440(10)63456-6. PubMed: 12937137

53. Garza LA, Yang CC, Zhao T, Blatt HB, Lee M et al. (2011) Bald scalp in men with androgenetic alopecia retains hair follicle stem cells but lacks CD200-rich and CD34-positive hair follicle progenitor cells. J Clin Invest 121: 613-622. doi:10.1172/JCl44478. PubMed: 21206086

54. Ohyama M, Terunuma A, Tock CL, Radonovich MF, Pise-Masison CA et al. (2006) Characterization and isolation of stem cell-enriched human hair follicle bulge cells. J Clin Invest 116: 249-260. PubMed: 16395407.

55. Vollmers A, Wallace L, Fullard N, Hoher T, Alexander MD et al. (2012) Two- and three-dimensional culture of keratinocyte stem and precursor cells derived from primary murine epidermal cultures. Stem. Cell Research 8: 402-413.

56. Rothnagel JA, Seki T, Ogo M, Longley MA, Wojcik SM et al. (1999) The mouse keratin 6 isoforms are differentially expressed in the hair follicle, footpad, tongue and activated epidermis. Differentiation 65: 119-130. doi:10.1046/j.1432-0436.1999.6520119.x. PubMed: 10550545.

57. Kaur P, Li A, Redvers R, Bertoncello I (2004) Keratinocyte stem cell assays: an evolving science. J Investig Dermatol Symp Proc 9: 238-247. doi:10.1111/j.1087-0024.2004.09306.x. PubMed: 15369219.

58. Sun X, Fu X, Han W, Zhao Y, Liu H et al. (2011) Dedifferentiation of human terminally differentiating keratinocytes into their precursor cells induced by basic fibroblast growth factor. Biol Pharm Bull 34: 1037-1045. doi:10.1248/bpb.34.1037. PubMed: 21720010.

59. Rosenblum MD, Yancey KB, Olasz EB, Truitt RL (2006) CD200, a "no danger" signal for hair follicles. J Dermatol Sci 41: 165-174. doi: 10.1016/j.jdermsci.2005.11.003. PubMed: 16386879.

60. Paus R, Nickoloff BJ, Ito T (2005) A 'hairy' privilege. Trends Immunol 26: 32-40. doi:10.1016/j.it.2004.09.014. PubMed: 15629407.

61. Harries MJ, Meyer K, Chaudhry I, Kloepper J, Poblet E et al. (2013) Lichen planopilaris is characterized by immune privilege collapse of the hair follicle's epithelial stem cell niche. Am J Pathol.

62. Stenn KS, Link R, Moellmann G, Madri J, Kuklinska E (1989) Dispase, a neutral protease from Bacillus polymyxa, is a powerful fibronectinase and type IV collagenase. J Invest Dermatol 93: 287-290. doi: 10.1111/1523-1747.ep12277593. PubMed: 2546994.

63. Link RE, Paus R, Stenn KS, Kuklinska E, Moellmann G (1990) Epithelial growth by rat vibrissae follicles in vitro requires mesenchymal contact via native extracellular matrix. J Invest Dermatol 95: 202-207. doi:10.1111/1523-1747.ep12478002. PubMed: 2380579.

64. Kleinman HK, McGarvey ML, Hassell JR, Star VL, Cannon FB et al. (1986) Basement membrane complexes with biological activity. Biochemistry 25: 312-318. doi:10.1021/bi00350a005. PubMed: 2937447.

65. Liu ZZ, Chen P, Lu ZD, Cui SD, Dong ZM (2011) Enrichment of breast cancer stem cells using a keratinocyte serum-free medium. Chin Med J (Engl) 124: 2934-2936. PubMed: 22040505

66. Mould AP, Akiyama SK, Humphries MJ (1996) The inhibitory anti-beta1 integrin monoclonal antibody 13 recognizes an epitope that is attenuated by ligand occupancy. Evidence for allosteric inhibition of integrin function. J Biol Chem 271: 20365-20374. doi:10.1074/jbc. 271.34.20365. PubMed: 8702772.

67. Mould AP, Garratt AN, Askari JA, Akiyama SK, Humphries MJ (1995) Identification of a novel anti-integrin monoclonal antibody that recognises a ligand-induced binding site epitope on the beta 1 subunit. FEBS Lett 363: 118-122. doi:10.1016/0014-5793(95)00301-O. PubMed: 7537221.

68. Hehlgans S, Haase M, Cordes N (2007) Signalling via integrins: implications for cell survival and anticancer strategies. Biochim Biophys Acta 1775: 163-180. PubMed: 17084981.

69. Gendronneau G, Sidhu SS, Delacour D, Dang T, Calonne C et al. (2008) Galectin-7 in the control of epidermal homeostasis after injury. Mol Biol Cell 19: 5541-5549. doi:10.1091/mbc.E08-02-0166. PubMed: 18829868.

70. Murphy DA, Courtneidge SA (2011) The 'ins' and 'outs' of podosomes and invadopodia: characteristics, formation and function. Nat Rev Mol Cell Biol 12: 413-426. doi:10.1038/nrm3141. PubMed: 21697900.

71. Cotsarelis G (2006) Epithelial stem cells: a folliculocentric view. J Invest Dermatol 126: 1459-1468. doi:10.1038/sj.jid.5700376. PubMed: 16778814

72. Akiyama SK, Yamada SS, Chen WT, Yamada KM (1989) Analysis of fibronectin receptor function with monoclonal antibodies: roles in cell 
adhesion, migration, matrix assembly, and cytoskeletal organization. J Cell Biol 109: 863-875. doi:10.1083/jcb.109.2.863. PubMed: 2527241.

73. Tuckwell DS, Smith L, Korda M, Askari JA, Santoso S et al. (2000) Monoclonal antibodies identify residues $199-216$ of the integrin alpha2 vWFA domain as a functionally important region within alpha2beta1. Biochem J 350 2: 485-493. doi:10.1042/0264-6021:3500485. PubMed: 10947963.

74. Gibson RM, Craig SE, Heenan L, Tournier C, Humphries MJ (2005) Activation of integrin alpha5beta1 delays apoptosis of Ntera2 neuronal cells. Mol Cell Neurosci 28: 588-598. doi:10.1016/j.mcn.2004.11.004. PubMed: 15737747.

75. Yu YP, Luo JH (2011) Phosphorylation and interaction of myopodin by integrin-link kinase lead to suppression of cell growth and motility in prostate cancer cells. Oncogene 30: 4855-4863. doi:10.1038/onc. 2011.200. PubMed: 21643011.

76. Widmaier M, Rognoni E, Radovanac K, Azimifar SB, Fässler R (2012) Integrin-linked kinase at a glance. J Cell Sci 125: 1839-1843. doi: 10.1242/jcs.093864. PubMed: 22637643.

77. Azimifar SB, Böttcher RT, Zanivan S, Grashoff $C$, Krüger $M$ et al. (2012) Induction of membrane circular dorsal ruffles requires cosignalling of integrin-ILK-complex and EGF receptor. J Cell Sci 125: 435-448. doi:10.1242/jcs.091652. PubMed: 22357970.

78. Judah D, Rudkouskaya A, Wilson R, Carter DE, Dagnino L (2012) Multiple roles of integrin-linked kinase in epidermal development, maturation and pigmentation revealed by molecular profiling. PLOS ONE 7: e36704. doi:10.1371/journal.pone.0036704. PubMed: 22574216.

79. Tehrani S, Tomasevic N, Weed S, Sakowicz R, Cooper JA (2007) Src phosphorylation of cortactin enhances actin assembly. Proc Natl Acad Sci U S A 104: 11933-11938. doi:10.1073/pnas.0701077104. PubMed: 17606906.

80. Attwell S, Roskelley C, Dedhar S (2000) The integrin-linked kinase (ILK) suppresses anoikis. Oncogene 19: 3811-3815. doi:10.1038/ sj.onc.1203711. PubMed: 10949937.

81. Kim YN, Koo KH, Sung JY, Yun UJ, Kim H (2012) Anoikis resistance: an essential prerequisite for tumor metastasis. Int J Cell Biol 2012: 306879

82. Fässler R, Meyer M (1995) Consequences of lack of beta 1 integrin gene expression in mice. Genes Dev 9: 1896-1908. doi:10.1101/gad. 9.15.1896. PubMed: 7544313.

83. Nakrieko KA, Welch I, Dupuis H, Bryce D, Pajak A et al. (2008) Impaired hair follicle morphogenesis and polarized keratinocyte movement upon conditional inactivation of integrin-linked kinase in the epidermis. Mol Biol Cell 19: 1462-1473. doi:10.1091/mbc.E07-06-0526. PubMed: 18234842.

84. Piwko-Czuchra A, Koegel H, Meyer H, Bauer M, Werner S et al. (2009) Beta1 integrin-mediated adhesion signalling is essential for epidermal progenitor cell expansion. PLOS ONE 4: e5488. doi:10.1371/ journal.pone.0005488. PubMed: 19424505.

85. Raghavan S, Bauer C, Mundschau G, Li Q, Fuchs E (2000) Conditional ablation of beta1 integrin in skin. Severe defects in epidermal proliferation, basement membrane formation, and hair follicle invagination. J Cell Biol 150: 1149-1160. doi:10.1083/jcb.150.5.1149. PubMed: 10974002.

86. Meng Y, Eshghi S, Li YJ, Schmidt R, Schaffer DV et al. (2010) Characterization of integrin engagement during defined human embryonic stem cell culture. FASEB J 24: 1056-1065. PubMed: 19933311.

87. Goel HL, Underwood JM, Nickerson JA, Hsieh CC, Languino LR (2010) Beta1 integrins mediate cell proliferation in three-dimensional cultures by regulating expression of the sonic hedgehog effector protein, GLI1. J Cell Physiol 224: 210-217. PubMed: 20333644.

88. Hotchin NA, Gandarillas A, Watt FM (1995) Regulation of cell surface beta 1 integrin levels during keratinocyte terminal differentiation. J Cell Biol 128: 1209-1219. doi:10.1083/jcb.128.6.1209. PubMed: 7534766.

89. López-Rovira T, Silva-Vargas V, Watt FM (2005) Different consequences of beta1 integrin deletion in neonatal and adult mouse epidermis reveal a context-dependent role of integrins in regulating proliferation, differentiation, and intercellular communication. J Invest
Dermatol 125: 1215-1227. doi:10.1111/j.0022-202X.2005.23956.x. PubMed: 16354192

90. Ohyama M, Kobayashi T (2012) Isolation and characterization of stem cell-enriched human and canine hair follicle keratinocytes. Methods Mol Biol 879: 389-401. doi:10.1007/978-1-61779-815-3_24. PubMed: 22610573.

91. Harries MJ, Paus R (2010) The pathogenesis of primary cicatricial alopecias. Am J Pathol 177: 2152-2162. doi:10.2353/ajpath. 2010.100454. PubMed: 20889564.

92. Byron A, Humphries JD, Humphries MJ (2013) Defining the extracellular matrix using proteomics. Int J Exp Pathol: ([MedlinePgn:]) PubMed: 23419153.

93. Aasen T, Izpisúa Belmonte JC (2010) Isolation and cultivation of human keratinocytes from skin or plucked hair for the generation of induced pluripotent stem cells. Nat Protoc 5: 371-382. doi:10.1038/ nprot.2009.241. PubMed: 20134422.

94. Stenn KS, Paus R (2001) Controls of hair follicle cycling. Physiol Rev 81: 449-494. PubMed: 11152763

95. Morisaki N, Ohuchi A, Moriwaki S (2013) The role of neprilysin in regulating the hair cycle. PLOS ONE 8: e55947. doi:10.1371/ journal.pone.0055947. PubMed: 23418484.

96. Ma W, Tavakoli T, Derby E, Serebryakova Y, Rao MS et al. (2008) Cell-extracellular matrix interactions regulate neural differentiation of human embryonic stem cells. BMC Dev Biol 8: 90. doi: 10.1186/1471-213X-8-90. PubMed: 18808690.

97. Uemura M, Refaat MM, Shinoyama M, Hayashi H, Hashimoto $N$ et al. (2010) Matrigel supports survival and neuronal differentiation of grafted embryonic stem cell-derived neural precursor cells. J Neurosci Res 88: 542-551. PubMed: 19774667.

98. Hughes CS, Postovit LM, Lajoie GA (2010) Matrigel: a complex protein mixture required for optimal growth of cell culture. Proteomics 10: 1886-1890. doi:10.1002/pmic.200900758. PubMed: 20162561.

99. Hannigan GE, McDonald PC, Walsh MP, Dedhar S (2011) Integrinlinked kinase: not so 'pseudo' after all. Oncogene 30: 4375-4385. doi: 10.1038/onc.2011.177. PubMed: 21602880

100. Wickström SA, Lange A, Montanez E, Fässler R (2010) The ILK/ $\mathrm{PINCH} /$ parvin complex: the kinase is dead, long live the pseudokinase! EMBO J 29: 281-291. PubMed: 20033063.

101. Maydan M, McDonald PC, Sanghera J, Yan J, Rallis C et al. (2010) Integrin-linked kinase is a functional Mn2+-dependent protein kinase that regulates glycogen synthase kinase-3beta (GSK-3beta) phosphorylation. PLOS ONE 5: e12356. doi:10.1371/journal.pone. 0012356. PubMed: 20827300.

102. Ghatak S, Morgner J, Wickström SA (2013) ILK: a pseudokinase with a unique function in the integrin-actin linkage. Biochem Soc Trans 41: 995-1001. doi:10.1042/BST20130062. PubMed: 23863169.

103. McDonald PC, Fielding AB, Dedhar S (2008) Integrin-linked kinase-essential roles in physiology and cancer biology. J Cell Sci 121: 3121-3132. doi:10.1242/jcs.017996. PubMed: 18799788.

104. Assi K, Patterson S, Dedhar S, Owen D, Levings M et al. (2011) Role of epithelial integrin-linked kinase in promoting intestinal inflammation: effects on CCL2, fibronectin and the T cell repertoire. BMC Immunol 12: 42. doi:10.1186/1471-2172-12-42. PubMed: 21806815.

105. Lorenz K, Grashoff C, Torka R, Sakai T, Langbein L et al. (2007) Integrin-linked kinase is required for epidermal and hair follicle morphogenesis. J Cell Biol 177: 501-513. doi:10.1083/jcb.200608125. PubMed: 17485490

106. Sakai T, Li S, Docheva D, Grashoff C, Sakai K et al. (2003) Integrinlinked kinase (ILK) is required for polarizing the epiblast, cell adhesion, and controlling actin accumulation. Genes Dev 17: 926-940. doi: 10.1101/gad.255603. PubMed: 12670870.

107. Devallière J, Chatelais M, Fitau J, Gérard N, Hulin P et al. (2012) LNK (SH2B3) is a key regulator of integrin signaling in endothelial cells and targets alpha-parvin to control cell adhesion and migration. FASEB J 26: 2592-2606. doi:10.1096/fj.11-193383. PubMed: 22441983.

108. Ohyama M, Veraitch O (2013) Strategies to enhance epithelialmesenchymal interactions for human hair follicle bioengineering. J Dermatol Sci 70: 78-87. doi:10.1016/j.jdermsci.2013.02.004. PubMed: 23557720. 